\title{
A Mathematical Model of the
}

\section{Ultrasound-Assisted Continuous Tubular Crystallization of Aspirin}

\author{
Symeon V. Savvopoulos, Mohammed N. Hussain, Jeroen Jordens, Steffen \\ Waldherr, Tom Van Gerven, and Simon Kuhn* \\ KU Leuven, Department of Chemical Engineering, Celestijnenlaan 200F, 3001 Leuven, \\ Belgium \\ E-mail: simon.kuhn@kuleuven.be \\ Phone: +3216322718
}

\begin{abstract}
Ultrasound-assisted nucleation is a promising method of controlling the crystal length within a narrow range in antisolvent crystallization. This article proposes novel model equations representing crystal nucleation and growth under ultrasound application in the antisolvent system of ethanol (solvent), water (antisolvent), and aspirin (pharmaceutical ingredient). The model considers the enhancement of nucleation by ultrasound, and also accounts for the heat generated from both the application of ultrasound and the mixing of solvent and antisolvent. We further employ a global sensitivity analysis to determine the parameters that have the most significant impact on model outputs before validating multiple experimental case studies that represent crystal growth for different antisolvent contents and initial supersaturation ratios. The model successfully captures the effect of the ultrasound, which is a function of temperature and supersaturation ratio, and has a strong impact on the refinement and the
\end{abstract}


quantity of the crystals. The proposed model offers a practical platform that can be applied to different scales and geometries in continuous crystallization systems using ultrasound.

\section{Introduction}

The crystallization of organic nano and microparticles is an important process for many industries, products, and applications. ${ }^{1}$ These particles are crucial for various applications, such as in the case of organic micron-sized crystals of active pharmaceutical ingredients (APIs) and nanodispersions of coating resins and microcapsules with active ingredients. ${ }^{1}$ The crystallization process itself can be performed in batch, semi-batch, and as continuous process. Currently, batch crystallization is widely implemented at large scale to meet market needs. However, the production of particles in batch processes is often associated with problems. The most common limitations in batch crystallizers are the difficulties faced during the control of heat and mass transfer, which are the factors that affect not only the average particle size and particle size distribution (PSD) but also batch-to-batch variations. The drawbacks of batch crystallization led researchers and industry initiatives to explore continuous processing technology, which enables the maintenance of higher product standards. $^{2}$ This work focuses on one of the most-used drugs, aspirin (acetylsalicylic acid ASA), as the crystallization model, and its mathematical novelty stems from the developing of high-fidelity models that will capture the lab-scale crystal production of the drug, including all heat transfer phenomena that occur and might affect the process. ${ }^{3}$ As for continuous processes, the most important advantages they provide are the ability to produce particles with specific particle sizes and smaller PSD. Additionally, the polymorphism can also be controlled. ${ }^{4}$ Plug flow crystallizers produce quantities on demand, effectively minimizing the use of raw materials and equipment, ${ }^{5}$ while they are also capable of being scaled up faster compared to batch systems. ${ }^{6}$ Population balance models (PBMs) are used extensively to describe crystallization processes as they capture the changes in the number and size of crystals over 
time. ${ }^{7}$ Hence, mathematical modelling was widely applied in recent years describing crystal production in continuous crystallizers, such as tubular crystallizers, ${ }^{8}$ and mixed suspension mixed product removal (MSMPR) crystallizers under silent conditions ${ }^{9}$ or with ultrasound. ${ }^{10}$ Ultrasound can be used for improving continuous crystallization processes as the generated cavitation bubbles may serve as nucleation sites, forming finer crystals with a low average size and narrower PSD. ${ }^{11-14}$ Ultrasound has been applied to different micro- or milli-fluidic continuous devices, such as slug-flow crystallizers, ${ }^{15}$ droplet-based crystallizers, ${ }^{16}$ plug flow ${ }^{17}$ and millichannels. ${ }^{18,19}$ These studies provide evidence that ultrasound affects nucleation and growth rates, however the detailed mechanism is yet to be clarified. In addition to the potential nucleation enhancing effect of the cavitation bubbles which decrease the temperature of the adjacent liquid significantly during their collapse, the bubbles' collapse can also cause attrition and breakage of larger crystals. ${ }^{10,20}$ In addition, secondary nucleation rates can be enhanced because sonication reduces the amount of agglomerated crystals due to fragmentation, and the increased fluid shear can form new nuclei from an existing crystal. ${ }^{20,21}$ Applying ultrasound also affects the crystal shape, e.g. in the case of benzoic acid, the crystal shape is hexagonal with sonication instead of needle shaped in silent conditions. ${ }^{22}$ Sonication was also found to reduce the induction time, however, longer irradiation times result in an increase of the mixture temperature, which in turn also affects the induction time. ${ }^{22,23}$ Lastly, ultrasound enhances micromixing which leads to the homogeneity of supersaturation. ${ }^{3}$

In the case of antisolvent crystallization, the nucleation and growth rates as well as the solubility are not only temperature dependant but also affected by the antisolvent content. ${ }^{8}$ Especially in the low range of antisolvent content the solubility curve exhibits significant changes for slight variations in antisolvent content and temperature. ${ }^{24}$ This also means that to properly model ultrasound-assisted antisolvent crystallization both the heat of mixing and the temperature increase due to ultrasound irradiation need to be captured. ${ }^{25}$

The overall objective of this article is to develop and validate a model for the ultrasoundassisted continuous antisolvent crystallization of aspirin. Diverging from previous mathe- 
matical models for the continuous antisolvent crystallization of aspirin, this article presents the first tubular crystallizer model that (1) considers the effect of ultrasound on the nucleation rate, (2) takes into consideration the heat generated due to mixing, (3) adds the experimentally measured calorimetric effect of ultrasound irradiation, and (4) predicts the crystal growth in the presence of ultrasound. This study aligns with the ongoing efforts for optimizing continuous crystallization processes and their scale-up.

\section{Material and Methods}

\subsection{Materials}

The solvent used was absolute ethanol (99\% pure), purchased from Fisher-Scientific. The antisolvent was distilled water. The API, 99\% pure Acetyl Salicylic Acid (ASA), was purchased from Sigma-Aldrich.

\subsection{Crystallization setup}

An ultrasound integrated flow crystallizer developed by John et al. ${ }^{26}$ for liquid-liquid extraction is used for the antisolvent sonocrystallization of ASA (Acetyl-Salicylic acid, Aspirin). The crystallizer consists of an aluminum housing with solid metal contacts at regular intervals that support the PFA tubing. The housing allows cooling water circulation for temperature control. A PFA tube (Bola Germany) having an inner diameter of $2 \mathrm{~mm}$, an outer diameter of $3 \mathrm{~mm}$, and a total length of $50 \mathrm{~cm}$ was used. The crystallizer (see Figure 1) with PFA tubes and a plexi-glass top cover is bolted to an ultrasonic transducer (Ultrasonics World $\left.{ }^{(}\right)$ MPI-7850D-20 40 60H). The piezoceramic material of the transducer contains lead zirconate titanate, and its front mass metal is aluminium (Al6061). ${ }^{27}$ The size of the plate bolted on the transducer is $6 \mathrm{~cm} \times 6 \mathrm{~cm}$ with a thickness of $1 \mathrm{~cm}$. The frequency was maintained constant at $42 \mathrm{kHz}$ with an EI 1020L radio frequency power amplifier and signal generator

Picotest LXI, G5100. All experiments were carried out at a power of $24 \mathrm{~W}$. A Pico ${ }^{\complement}$ TC-08 
thermocouple data logger with type-K thermocouples was used for temperature recording. Two pulse-free gear pumps (ISMATEC REGLO-Z digital, Z186 pump head) were used to pump the solution and antisolvent respectively. A Lauda ${ }^{(}$thermal bath (Silver ECO 620) with a Pt100 thermocouple, running at $22 \mathrm{~L} / \mathrm{min}$, was used to control the temperature.

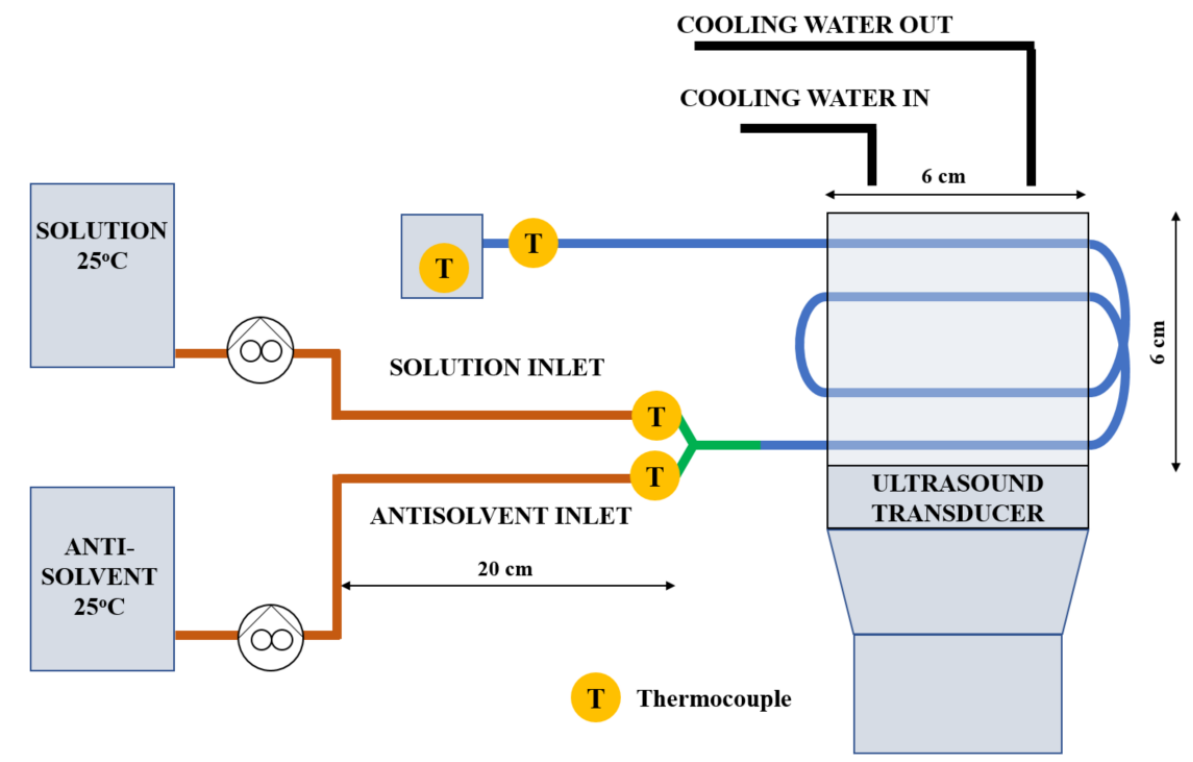

Figure 1: Experimental setup (the crystallizer has been labelled for clarity, the transducer surface is in full contact with the flat bottom of the crystallizer).

\subsection{Crystallization procedure}

The solution and antisolvent were pre-heated to $25^{\circ} \mathrm{C}$ in separate feed containers with IKA ${ }^{\circledR}$ heating plates. The solubility of ASA in ethanol was obtained from the relevant literature. ${ }^{24}$ For each initial concentration, a specific weight of ASA was added to a measured volume of ethanol and stirred for at least $2 \mathrm{~h}$ at $800 \mathrm{RPM}$. A 'Y' connector, with a bore size of $1.5 \mathrm{~mm}$, was used to mix the solution and antisolvent streams right before they enter the crystallizer. The tubing length between the 'Y' connector and crystallizer entrance was $1 / 10$ th $(5 \mathrm{~cm})$ of the total tubing length. Therefore, a single stream of solution with antisolvent enters the crystallizer. Experiments are carried out at different initial API concentrations and antisolvent wt\% for each starting concentration. The solution flow rate is kept constant at 
$2 \mathrm{ml} / \mathrm{min}$, whereas the antisolvent flow rate is varied to achieve the desired antisolvent wt\% (solute free basis). Table 1 presents the details of the flow rates, antisolvent wt\%, the inlet concentration of the API, and supersaturation ratio, while Table 2 shows the characteristics of the crystals produced for each experiment. No crystallization was noticed in silent conditions as the induction time is much larger than the residence time. ${ }^{3}$

To ensure a steady state, the combined flow of solution and antisolvent is allowed to run for 20 residence times in the crystallizer. Only after this, ultrasound is applied. Crystallization is detected visually.

For analyzing the yield, the experiment was first allowed to run for 20 residence times to ensure a steady state, then ultrasound was switched on. Once crystallization was noticed, the outflowing slurry was instantaneously filtered with a $0.22 \mu \mathrm{m}$ filter in a vacuum filtration setup for $3 \mathrm{~min}$. The residue was air-dried for at least $36 \mathrm{~h}$ and then weighed along with the filter to avoid losses and errors. The dry weight of the filter was then subtracted.

Table 1: Flow rates, antisolvent wt \%, initial concentration, and supersaturation ratio for the 5 different experimental cases.

\begin{tabular}{cccccc}
\hline Cases & $\begin{array}{c}\text { Solution flow rate } \\
(\mathbf{m L} / \mathbf{m i n})\end{array}$ & $\begin{array}{c}\text { Antisolvent } \\
\text { flow rate } \\
(\mathbf{m L} / \mathbf{m i n})\end{array}$ & $\begin{array}{c}\text { Antisolvent } \\
(\mathbf{w t} \%)\end{array}$ & $\begin{array}{c}\text { Inlet concentration } \\
(\mathrm{g} / \mathbf{k g})\end{array}$ & $\begin{array}{c}\text { Supersaturation ratio } \\
(-)\end{array}$ \\
\hline 1 & 2 & 4 & 73.33 & 56.10 & 2.40 \\
2 & 2 & 3 & 67.90 & 92.41 & 2.42 \\
3 & 2 & 6 & 80.61 & 53.40 & 2.67 \\
4 & 2 & 6 & 81.06 & 72.20 & 3.61 \\
5 & 2 & 9 & 86.52 & 50.00 & 2.50
\end{tabular}

\subsection{Particle size analysis}

A Malvern Mastersizer 3000 Hydro SV laser diffractometer was used to analyze the particle sizes (Figure 2). Hexane (purity > 99\%; Chemlab ` NV, Belgium) was used as a dispersant, and the background analysis was conducted with pure hexane. Sample (ASA) was then added to $7 \mathrm{~mL}$ of dispersant until an obscuration of at least $3 \%$ was reached. The refractive index of ASA was set to 1.56, absorption index to 1 , and stirring speed was 1800 RPM. 5 
measurements were taken for each sample such that the relative standard deviation (RSD) was less than 5\% for Dv10 and 3\% for Dv50 and Dv90 (Dv50 is the median for a volume distribution; Dv10, and Dv90 correspond to the sizes at which the cumulative volume distribution reaches $10 \%$, and $90 \%$, respectively). The average of these values is presented in Table 2 . At least 3 cleaning cycles were conducted before analyzing a new sample.

\section{Mathematical Model}

\subsection{General Model}

The general model in continuous ultrasound crystallization consists of the population balance model of the crystals, the solute mass balance, the supersaturation ratio, and the energy balance. $^{8,28}$ As the crystallization is performed in a milifluidic crystallizer and ultrasound is known to enhance mixing, the crystallizer is modelled as a plug flow crystallizer. The population balance model includes the terms as change in crystal number density with time, change in crystal number density with growth, change in crystal number density with change in the solution/slurry volume due to the addition of antisolvent, nucleation rate, agglomeration, and breakage. For simplifying the simulation, the breakage and agglomeration terms were neglected. ${ }^{22}$ The crystals' population balance model is then given by:

$$
\frac{\partial n}{\partial t}+\frac{\partial\left(v_{z} n\right)}{\partial z}+\frac{\partial(G n)}{\partial L}=0
$$

Table 2: Characteristic sizes of the crystals obtained for the 5 experimental cases detailed in Table 1.

\begin{tabular}{ccccc}
\hline Cases & Dv10 $(\mu \mathbf{m})$ & Dv50 $(\mu \mathbf{m})$ & Dv90 $(\mu \mathbf{m})$ & Yield $(\%)$ \\
\hline 1 & 4.33 & 17.00 & 45.50 & $\approx 40$ \\
2 & 3.98 & 11.20 & 30.80 & $\approx 40$ \\
3 & 5.85 & 19.70 & 44.20 & $\approx 40$ \\
4 & 3.85 & 11.00 & 21.80 & $\approx 40$ \\
5 & 3.97 & 12.30 & 26.20 & $\approx 34$
\end{tabular}


Case 1

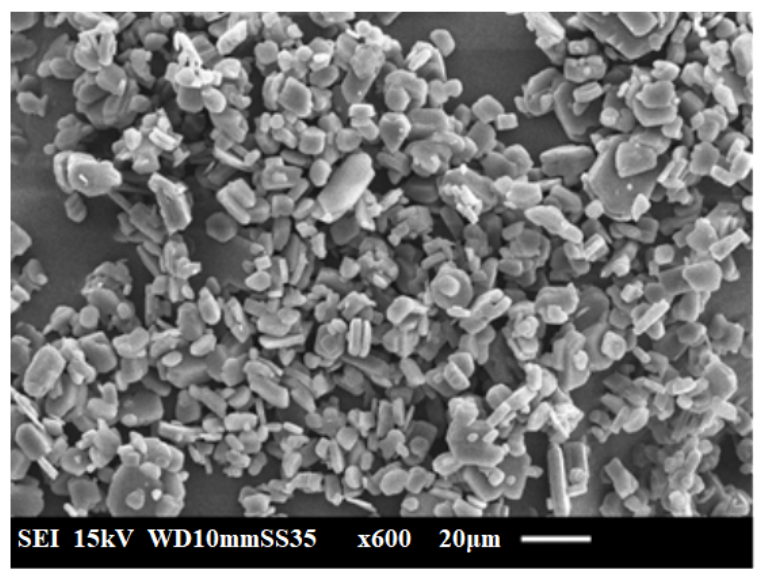

Case 3

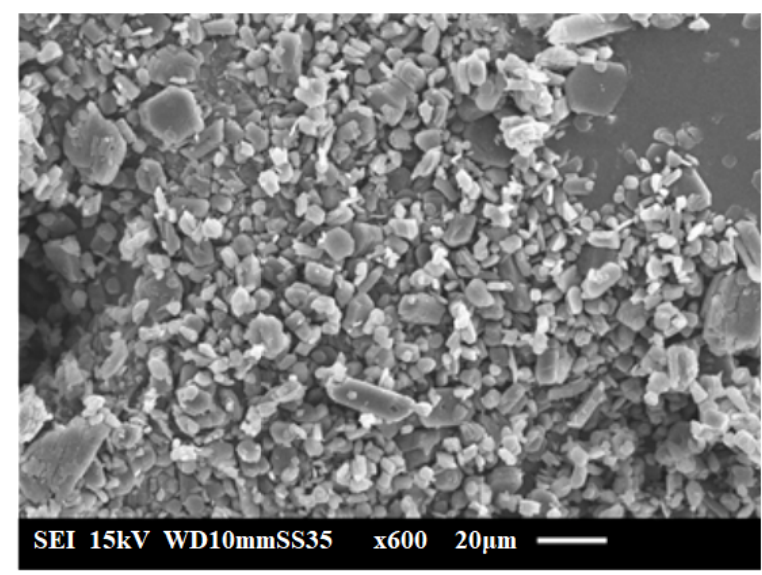

Case 2

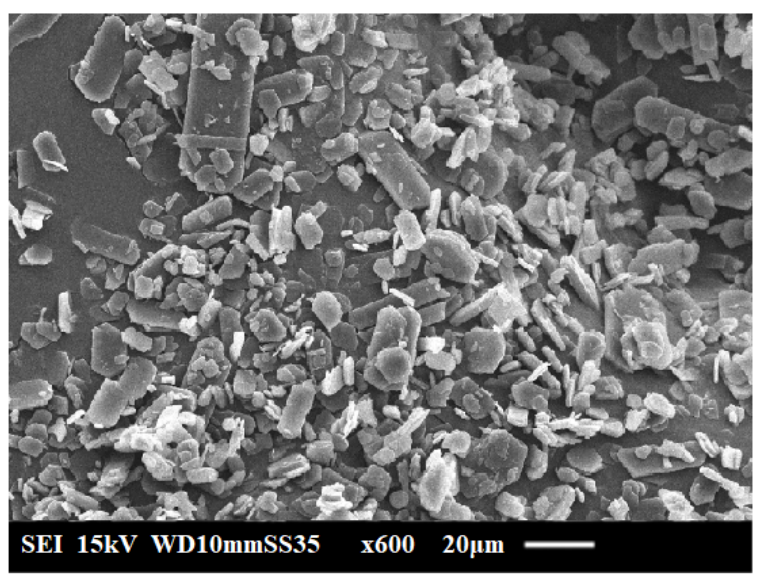

Case 4

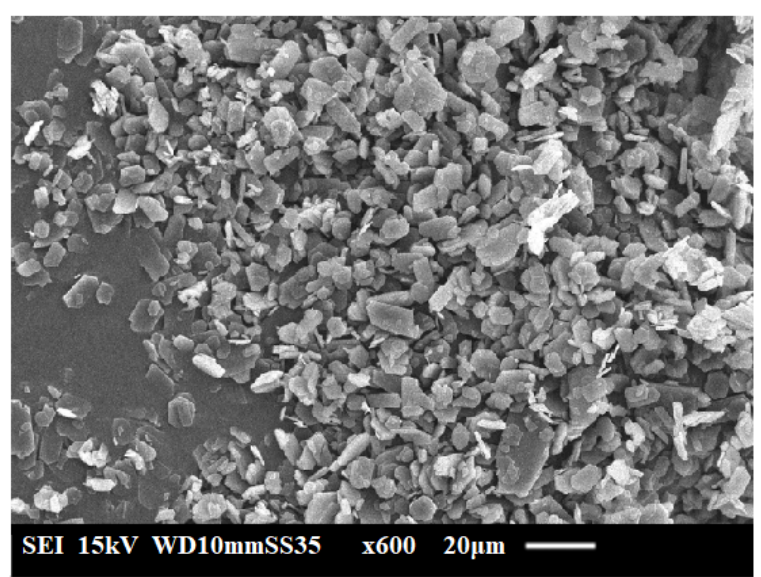

\section{Case 5}

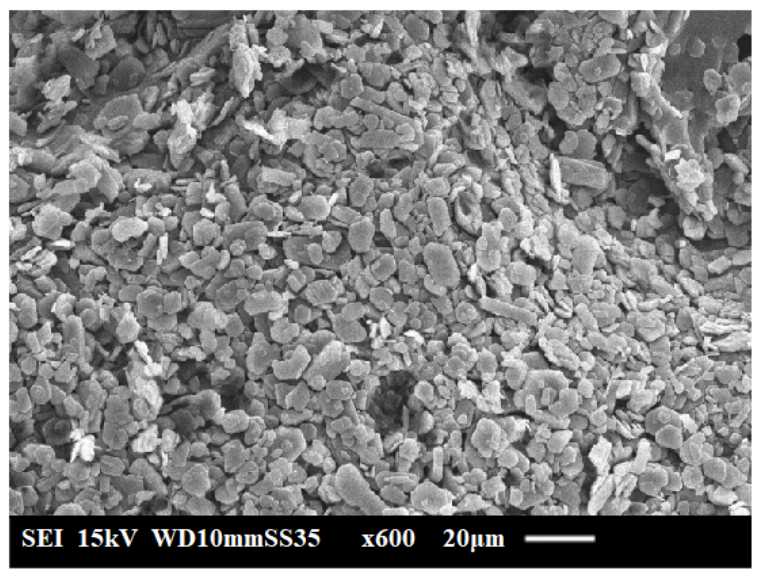

Figure 2: SEM analysis of crystals obtained for the 5 experimental cases detailed in Table 1. 
where $n$ represents the number probability density function of crystals in the slurry $\left[\# /\left(\mathrm{m}^{3} \mathrm{~m}\right)\right]$, $t$ is the time $[\mathrm{s}], v_{z}$ is the slurry velocity along the crystallizer $[\mathrm{m} / \mathrm{s}], z$ is the axial position in the crystallizer $[\mathrm{m}], G$ is the crystal growth rate $[\mathrm{m} / \mathrm{s}]$, and $L$ is the characteristic crystal length $[\mathrm{m}]$. The slurry velocity $v_{z}$ is calculated from:

$$
v_{z}=\frac{4\left(Q_{\text {solv }}+Q_{a n t i}\right)}{\pi d_{i n}^{2}}
$$

where $Q_{\text {solv }}$ is the volumetric flow rate of the solvent with the solute $\left[\mathrm{m}^{3} / \mathrm{s}\right], Q_{\text {anti }}$ is the volumetric flowrate of the antisolvent $\left[\mathrm{m}^{3} / \mathrm{s}\right]$, and $d_{i n}$ is the inner diameter of the channel $[\mathrm{m}]$.

The solute mass balance is:

$$
\frac{\partial C}{\partial t}+\frac{\partial\left(v_{z} C\right)}{\partial z}+3 \rho_{c} K_{v} \int G L^{2} n d L=0
$$

where $C$ is the concentration of the aspirin in the solution $\left[\mathrm{kg} / \mathrm{m}^{3}\right], \rho_{c}$ is the crystal density which equals $1400 \mathrm{~kg} / \mathrm{m}^{3}$, and $K_{v}$ is the volumetric shape factor of a crystal and equals to $1[-]$.

The energy balance is:

$$
\frac{\partial T}{\partial t}=-v_{z} \frac{\partial T}{\partial z}-\frac{U_{c} a_{c}}{\rho C p}\left(T-T_{w}\right)+\frac{P_{n e t, c a l}}{\rho C p}
$$

where $T$ is the temperature $[\mathrm{K}], T_{w}$ is the wall temperature where the cooling water affects the system temperature $[\mathrm{K}], U_{c}$ is the overall heat transfer coefficient which equals $150 \mathrm{~J} /\left(\mathrm{m}^{2}\right.$ $\mathrm{S} \mathrm{K}),{ }^{29} a_{c}$ is the heat transfer area per unit volume $\left(4 / d_{i n}\right)^{28}\left[\mathrm{~m}^{2} / \mathrm{m}^{3}\right], C p$ is the mixture specific heat capacity which equals $4130 \mathrm{~J} /(\mathrm{kg} \mathrm{K}),{ }^{30} \rho$ is the mixture density which equals $1000 \mathrm{~kg} / \mathrm{m}^{3}, 31$ and $P_{\text {net,cal }}$ is the calorimetric power of ultrasound $\left[\mathrm{W} / \mathrm{m}^{3}\right]$, which is (see 
section A1 in the Supplementary Material):

$$
P_{n e t, c a l}=66230.5 P_{n e t, U S}
$$

where $P_{n e t, U S}$ is the applied ultrasound power [W].

The number density $n$, the solute concentrations $C$, and the energy balance are given by partial differential equations; thus, they are functions of the crystallizer axial position $z$ and time $t$. The boundary conditions of Eqs. 1, 3, and 4 are:

$$
\begin{gathered}
n\left(L_{0}, z, t\right)=\frac{B_{\text {son }}}{G} \\
n(L, 0, t)=n_{\text {feed }}(L, t) \\
C(0, t)=C_{\text {feed }} \\
T(0, t)=T_{\text {feed }}-f_{\text {mix }} \frac{\Delta H_{\text {mix }}}{C p}
\end{gathered}
$$

where $B_{\text {son }}$ is the nucleation rate $\left[\# /\left(\mathrm{m}^{3} \mathrm{~s}\right)\right]$ from ultrasound, $L_{0}$ is the nuclei size $[\mathrm{m}], n_{\text {feed }}$ is the crystal size distribution at the inlet of the crystallizer (which should be known in a seeded crystallization $\left[\# /\left(\mathrm{m}^{3} \mathrm{~m}\right)\right]$, or in a feed supplied slurry from an upstream process), and $C_{f e e d}$ is the concentration at the crystallizer inlet. As for the energy balance, $T_{f e e d}$ is the inlet temperature $[\mathrm{K}], f_{\text {mix }}$ is an empirical factor that indicates the mixing (calculated in section A2 in the Supplementary Material) [-], and $\Delta H_{m i x}$ is the enthalpy of mixing $[\mathrm{J} / \mathrm{kg}]^{25}$.

Furthermore, the initial conditions of Eqs. 1, 3, and 4 are:

$$
n(L, z, 0)=n_{0}(L, z)
$$




$$
\begin{aligned}
& C(z, 0)=C_{0} \\
& T(z, 0)=T_{i n}
\end{aligned}
$$

where $n_{0}$ and $C_{0}$ are the initial number probability density function for the CSD and solute concentration respectively, within the crystallizer, and $T_{i n}$ is the initial temperature.

\subsection{Nucleation, growth rates and yield of the system}

For the antisolvent system ethanol, water, and aspirin, the solute solubility $C_{\text {sat }}[\mathrm{g} / \mathrm{kg}]$ in

silent conditions is obtained using the work of Lindenberg et al.,${ }^{24}$ where $C_{\text {sat }}[\mathrm{g} / \mathrm{kg}]$ is expressed as a function of the mixture temperature $\theta\left[{ }^{\circ} \mathrm{C}\right]$ and the antisolvent content, $w$, according to:

$$
C_{s a t}=p_{0,0} w^{0} \theta^{0}+p_{1,0} w^{1} \theta^{0}+p_{0,1} w^{0} \theta^{1}+p_{1,1} w^{1} \theta^{1}+p_{0,2} w^{0} \theta^{2}+\ldots+p_{0,6} w^{0} \theta^{6}
$$

where the parameters $p_{i, j}$ are the elements of the $i^{\text {th }}$ row and $j^{\text {th }}$ column given in Table A1 in section A3 in the Supplementary Material.

The supersaturation ratio $S[-]$ is:

$$
S=\frac{C_{w}}{C_{\text {sat }}}
$$

where $C_{w}$ is the aspirin concentration in $[\mathrm{kg} / \mathrm{kg}]$.

The nucleation rate consists of the nucleation caused by ultrasound, $B_{u l t r}$, and secondary 
nucleation, $B_{\text {sec }}$. When $S>1$, the nucleation rate is:

$$
\begin{aligned}
& B_{\text {son }}=B_{u l t r}+B_{\text {sec }} \\
& B_{u l t r}=k_{j 1, \text { son }} \exp \left(\frac{k_{j 2, \text { son }}}{R T}\right) \exp \left(-\frac{k_{j 3, \text { son }}}{l n^{2} S}\right) \\
& B_{\text {sec }}=k_{\text {sec }, 1} \exp \left(-k_{\text {sec }, 2} w\right)(S-1)^{2} \mu_{2}
\end{aligned}
$$

where $k_{j 1, \text { son }}\left[\# /\left(\mathrm{m}^{3} \mathrm{~s}\right)\right], k_{j 2, \text { son }}[\mathrm{J} / \mathrm{mol}], k_{j 3, \text { son }}[-], k_{\text {sec }, 1}\left[\# /\left(\mathrm{m}^{2} \mathrm{~s}\right)\right]$ and $k_{\text {sec }, 2}[-]$ are all empirical parameters, and $\mu_{2}$ is the second moment of $n\left[\mathrm{~m}^{2} / \mathrm{m}^{3}\right]$, estimated as:

$$
\mu_{2}=\int L^{2} n d L
$$

The empirical parameters used here affect the evolution of the nucleation rate at different temperatures and supersaturation ratio values.

Figure 3 depicts the surface of the nucleation rate due to ultrasound calculated from Eq. 15 as a function of supersaturation ratio and temperature. This equation is based on experimental measurements in our previous work. ${ }^{17}$ In these experiments, the higher the supersaturation ratio was, the smaller the crystals were, and at lower temperatures the crystal size also becomes lower - until a threshold was reached. Having small crystals entails a high nucleation rate and, after a certain supersaturation ratio, a plateau appears in the nucleation rate, as shown in Figure 3. Furthermore, nucleation from ultrasound should be higher when $S$ is high and temperature is low, while nucleation decreases when the temperature increases. With regard to secondary nucleation, while there are various expressions in literature, it is always proportional to the solubility and the second moment $\mu_{2} \cdot{ }^{32,33}$ In our case, the antisolvent content was also included in the secondary nucleation, which is similar to the antisolvent system of paracetamol. ${ }^{8}$

The growth rate when $S>1$ is:

$$
G=k_{G 1} \exp \left(-\frac{k_{G 2}}{R T}\right)\left(C_{s a t}(S-1)\right)
$$


where $k_{G 1}[\mathrm{~m} / \mathrm{s}]$ and $k_{G 2}[\mathrm{~J} / \mathrm{mol}]$ are empirical parameters that affect the crystal growth rate at different supersaturation ratios $S$ and temperatures $T$. The yield [-] of our system is: ${ }^{34}$

$$
\text { yield }=1-\frac{C\left(z_{\max }, t\right)}{C(z=0, t)}
$$

Due to temperature increase in the crystallizer, the loss in the yield of our system is (see Figure 4):

$$
\text { loss }=\frac{\text { yield }_{T=25^{\circ} \mathrm{C}}-\text { yield }}{\text { yield }_{T=25^{\circ} \mathrm{C}}}
$$

where yield $_{T=25^{\circ} \mathrm{C}}$ is the yield when the system reaches its steady state at $25^{\circ} \mathrm{C}$.

The crystal volume over the slurry volume $\left[\mathrm{m}^{3} / \mathrm{m}^{3}\right]$ is:

$$
V=\int k_{v} L^{3} n d L
$$

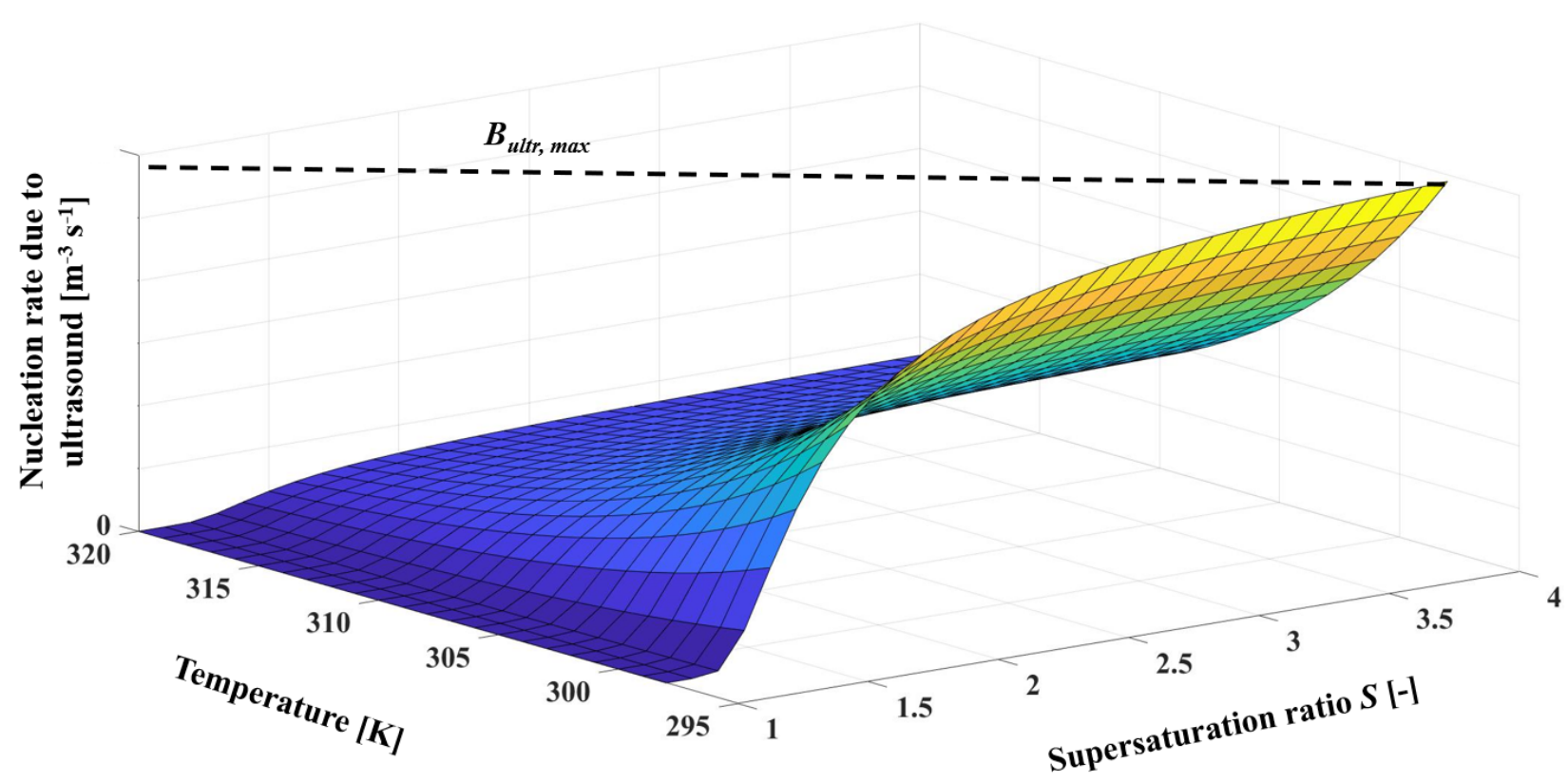

Figure 3: Nucleation rate due to ultrasound as a function of temperature and supersaturation ratio. The nucleation rate increases as $S$ increases, reaching a maximum value $\left(B_{\text {son, } \max }\right)$. However, it decreases at higher temperatures. 


\subsection{Global sensitivity analysis}

For the global sensitivity analysis, we apply a random sampling high-dimensional model representation (RS-HDMR) analysis to the nominal parameter values. The parameter values in Table 3 have a range of $\pm 20 \%{ }^{35}$ and are used as inputs for the RS-HDMR model analysis (see section A4 in the Supplementary Material). In the nucleation rate of the sonicated population, we assumed similar values of the exponential terms $\left(k_{s o n, 2}\right.$ and $\left.k_{s o n, 3}\right)$ as in the work of Lindenberg et al., ${ }^{24}$ but we used a value of $k_{\text {son }, 1}=1.150 \cdot 10^{-7} \# /\left(\mathrm{m}^{3} \mathrm{~s}\right)$. The value of $k_{s o n, 1}$ was chosen so that it generates a nucleation rate up to 2 orders of magnitude lower than that in silent conditions $\left(10^{8}\right)^{24}$ to account for the low mixing in our crystallizer in comparison with a batch system mixed by an impeller. Inspired by the work of Frawley et $\mathrm{al}^{33}$ which showed that the secondary nucleation rate is greater than the primary, an initial parameter set for the secondary nucleation rate, $k_{s e c, 1}$ and $k_{s e c, 2}$, was assumed to be equal to $1.150 \cdot 10^{11} \# /\left(\mathrm{m}^{2} \mathrm{~s}\right)$ and 0.030 respectively. The value $k_{\text {sec, } 1}$ was selected because it generates a nucleation rate greater than the ultrasound nucleation which is of the order of $10^{6}$. The initial nominal value of $k_{s e c, 2}$ was assumed by us for sensitivity analysis. Nominal values of $k_{G 1}$ and $k_{G 2}$ stem from the literature. ${ }^{24}$ The RS-HDMR output variables are $n$, the crystals' volume in the crystallizer outlet, and the API concentration. We tested the sizes $1,5,10$, and $15 \mu \mathrm{m}$ for our crystal population. The global sensitivity analysis reveals the critical parameters, which will then be estimated based on the obtained experimental

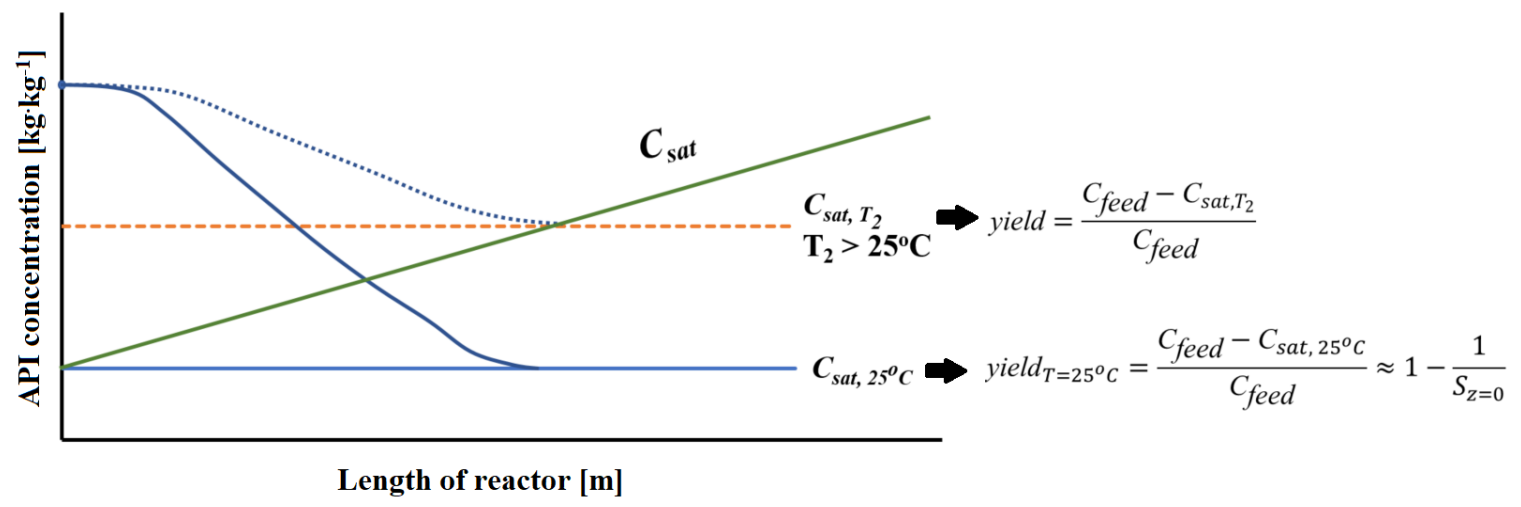

Figure 4: Theoretical yield change due to a temperature increase along the crystallizer length. 
measurements.

\subsection{Parameter estimation via Maximum Likelihood}

All parameter estimation experiments and simulations were performed on a $4.40 \mathrm{GHz}$ Intel Core i7-4770 processor with 8 GB RAM, running 64-bit Windows 10. Both simulations and parameter estimation experiments were implemented in the advanced process modelling environment gPROMS. ${ }^{36}$ In gPROMS, the parameter estimation is based on the Maximum Likelihood formulation, which provides estimation of parameters in both the physical model of the process as well as the variance model of the measuring instruments. gPROMS has the ability to determine values for the uncertain physical and variance model parameters that maximise the probability of the mathematical model predicting the measurement values obtained from the experiments. In parameter estimation, the measurement errors, $\epsilon_{i j k}$, are assumed to be independent, normally distributed, with zero means and standard deviations, $\sigma_{i j k}$. The objective function that can capture this maximum likelihood goal is:

$$
\Phi=\frac{N}{2} \ln (2 \pi)+\frac{1}{2} \min _{p}\left\{\sum_{i=1}^{N E} \sum_{j=1}^{N V_{i}} \sum_{k=1}^{N M_{i j}}\left[\ln \left(\sigma_{i j k}^{2}\right)+\frac{\left(\bar{\zeta}_{i j k}-\zeta_{i j k}\right)^{2}}{\sigma_{i j k}^{2}}\right]\right\}
$$

where $N$ represents the total number of all measurements , $p$ is the set of model parameters to be estimated, $N E$ is the number of experiments performed, $N V_{i}$ is the number of variables measured in the $i^{t h}$ experiment, and $N M_{i j}$ is the number of measurements of the $j^{\text {th }}$ variable in the $i^{t h}$ experiment. The variance of the $k^{t h}$ measurement of variable $j$ in experiment $i$ is

denoted as $\sigma_{i j k}^{2}$, while $\bar{\zeta}_{i j k}$ is the $k^{t h}$ measured value of variable $j$ in experiment $i$ and $\zeta_{i j k}$ is the $k^{\text {th }}$ (model) predicted value of variable $j$ in experiment $i$. 


\section{Results and discussion}

\subsection{Global Sensitivity Analysis}

RS-HDMR analysis of the continuous crystallizer system is performed in sonicated conditions when $Q_{a n t i}=4 \mathrm{~mL} / \mathrm{min}, Q_{\text {solv }}=2 \mathrm{~mL} / \mathrm{min}, w=73.33 \%$ and $S=2.40$. The nominal parameter values are given in Table 3 and due to a low standard deviation estimated experimentally, these parameters were in the $\pm 20 \%$ range in the analysis. 2000 HDMR samples were performed in Matlab with the ordinary differential equations solver ode45. The tested outputs were the total number of crystals produced under sonicated conditions at different sizes at the crystallizer outlet, the concentration of API at the outlet, and the volume of the sonicated produced crystals over the volume of the slurry. The CPU time required for the RS-HDMR analysis including the estimation of the sensitivity indices was 90 min. Based on the analysis in the work of Ziehn and Tomlin, ${ }^{35}$ the parameters' rank of this model, which most significantly affect crystal formation over space and size, are (i) the parameter $k_{j 2, \text { son }}$ of the sonicated nucleation rate, (ii) the experimental parameter $k_{G 2}$ in the growth rate, and (iii) the $k_{s e c, 2}$ of the secondary nucleation rate. For the concentration and the volumes, the most significant parameters are $k_{j 2, \text { son }}$ and $k_{G 2}$ (see Table 4 ).

Table 3: Results of the parameter estimation via Maximum Likelihood. The parameter estimation was performed with $\sigma=0.02$ in all Dv measurements, and $\sigma=0.001$ in outlet concentrations. ${ }^{37}$

\begin{tabular}{ccccc}
\hline Parameter & Nominal Value & Units & Estimated Value & 95\% Conf. Interval \\
\hline$f_{\text {mix }}$ & 0.112 & $\mathrm{n} / \mathrm{a}$ & & \\
$k_{j 1, \text { son }}$ & $1.150 \cdot 10^{-7}$ & $\# /\left(\mathrm{m}^{3} \mathrm{~s}\right)$ & & \\
$k_{j 2, \text { son }}$ & $7.67 \cdot 10^{4}$ & $\mathrm{~J} / \mathrm{mol}$ & 102696.000 & 10000.000 \\
$k_{j 3, \text { son }}$ & 0.16 & $\mathrm{n} / \mathrm{a}$ & & \\
$k_{G 1}$ & $3.21 \cdot 10^{-4}$ & $\mathrm{~m} / \mathrm{s}$ & & \\
$k_{G 2}$ & $2.58 \cdot 10^{4}$ & $\mathrm{~J} / \mathrm{mol}$ & 19652.720 & \\
$k_{\text {sec }, 1}$ & $1.150 \cdot 10^{11}$ & $\# /\left(\mathrm{m}^{2} \mathrm{~s}\right)$ & & 0.0081 \\
$k_{\text {sec }, 2}$ & 0.030 & $\mathrm{n} / \mathrm{a}$ & 0.0103 &
\end{tabular}


Table 4: First- and second-order sensitivity indices for the studied outputs by varying the nominal parameter values in Table 3 by $\pm 20 \%$. The outputs are the density of crystals at 1 , 5,10 , and $15 \mu \mathrm{m}$ at the outlet, the API concentration at the outlet, and the crystal volume over the slurry volume at the outlet of the crystallizer.

\begin{tabular}{cccccccc}
\hline Parameter & SI index & $\mathbf{n}_{L=1 \mu m}$ & $\mathbf{n}_{L=5 \mu m}$ & $\mathbf{n}_{L=10 \mu m}$ & $\mathbf{n}_{L=15 \mu m}$ & $\mathbf{C}_{z=0.5 m}$ & $\mathbf{V}_{z=0.5 m}$ \\
\hline$f_{\text {mix }}$ & $S_{1}$ & 0.0000 & 0.0000 & 0.0000 & 0.0005 & 0.0025 & 0.0004 \\
$k_{j 1, \text { son }}$ & $S_{2}$ & 0.0012 & 0.0014 & 0.0014 & 0.0016 & 0.0003 & 0.0003 \\
$k_{j 2, \text { son }}$ & $S_{3}$ & 0.5584 & 0.6287 & 0.6379 & 0.5249 & 0.2425 & 0.0894 \\
$k_{j 3, \text { son }}$ & $S_{4}$ & 0.0011 & 0.0002 & 0.0062 & 0.0011 & 0.0007 & 0.0006 \\
$k_{G 1}$ & $S_{5}$ & 0.0002 & 0.0001 & 0.0000 & 0.0003 & 0.0044 & 0.0076 \\
$k_{G 2}$ & $S_{6}$ & 0.0335 & 0.0247 & 0.0369 & 0.1062 & 0.5309 & 0.7152 \\
$k_{\text {sec, } 1}$ & $S_{7}$ & 0.0050 & 0.0057 & 0.0063 & 0.0061 & 0.0012 & 0.0000 \\
$k_{\text {sec, },}$ & $S_{8}$ & 0.0232 & 0.0296 & 0.0296 & 0.0281 & 0.0064 & 0.0005 \\
& $S_{3,6}$ & 0.2748 & 0.2118 & 0.1710 & 0.2405 & 0.1814 & 0.1619 \\
& $S_{3,8}$ & 0.0470 & 0.0510 & 0.0438 & 0.0207 & - & -
\end{tabular}

\subsection{Parameter estimation experiments}

The model presented above was applied to two different experiments. Parameter estimation was performed in gPROMS, and the parameter values concerning nucleation and growth (given in Table 3) were obtained from a batch experiment during silent conditions. The conditions under which parameter estimation is applied, Cases 1 and 2, are given in Table 1. During parameter estimation, it was assumed that the experimental measurements were obtained during steady state conditions, as the sampling time was at least ten times greater than the residence time of the crystallizer. The upwind discretization scheme was applied to the crystal size $L{ }^{28}$ Further, due to the fact that the sampling along a crystallizer is quite difficult to achieve, and only Dv10, Dv50, and Dv90 in the outlet are known, the parameter estimation was performed in two positions only (see Figure 5) based on the volume densities at different crystal lengths $\left(V_{\%, D v}\right)$. The first position was at $z=0.01 \mathrm{~m}$, where the values of $\int V_{\%, \text { Dv50 }} d L_{\text {Dv50 }}$ and $\int V_{\%, \text { Dv90 }} d L_{\text {Dv90 }}$ were all equal to $100 \%$, as close to the inlet the CSD is narrow compared to the population at the outlet. Thus, the cumulative distribution function of the volume density at that crystallizer length is equal to $100 \%$ at the Dv50, and Dv90 lengths at the outlet. The second location was $z=0.5 \mathrm{~m}$, corresponding to the crystallizer 
outlet, where the values of $\int V_{\%, \text { Dv10 }} d L_{\text {Dv10 }}, \int V_{\%, \text { Dv50 }} d L_{\text {Dv50 }}$ and $\int V_{\%, \text { Dv90 }} d L_{\text {Dv90 }}$ were $10 \%$, $50 \%$, and $90 \%$, respectively. Although the yield of the crystals not passing through the filter at the crystallizer outlet was approximately $40 \%$ of the initial API concentration, the concentration at the outlet in parameter estimation was considered equal to $60 \%$ of the API concentration in the inlet. A weighting factor of 0.005 was used to the concentration $C$ at the outlet, so that the concentration had the same order of magnitude as the Dv percentages. ${ }^{28,38}$

We apply the maximum likelihood parameter estimation algorithm with some extra multistarting steps for the same assumed and measured $\int V_{\%, \text { Dv10 }} d L_{\text {Dv10 }}, \int V_{\%, \text { Dv50 }} d L_{\text {Dv50 }}$ and $\int V_{\%, \text { Dv90 }} d L_{\mathrm{Dv} 90}$ and API concentration for determining the significant parameters of the 2 case studies. It is well known that the maximum likelihood estimator can be highly nonlinear and nonconvex in the model parameters. Therefore, the maximum likelihood estimator converges to local solutions depending on the initial nominal values of the parameters. The Multi-start local methods can be used for finding different solutions and, subsequently, a global optimum. ${ }^{39}$ These methods have been suggested as more robust alternatives. Usually, the generation of the set of the initial nominal values inside the parameter ranges is performed randomly. In our analysis, this estimated parameter set is given in Table 3 . The CPU time for a parameter estimation was about $40 \mathrm{sec}$. Next, for model validation, we use the same parameter set, and we simulate the CSDs of three different experiments, Cases 3, 4, and 5 in Table 1, and check its predictability. We also considered the yield of the system. These three experiments had different antisolvent flow rates and supersaturation ratios $S$.

Figures $6 \mathrm{~A}$ and $7 \mathrm{~A}$ show the modelled and experimentally measured CSDs of the Cases 1 and 2 in Table 1, while Figures $6 \mathrm{~B}$ and $7 \mathrm{~B}$ represent the API concentration and the temperature profile along the crystallizer for the same cases. Additionally, the yield is estimated and compared with isothermal conditions. Similarly, Figures 8A, 9A and 10A show the model prediction of the experimentally measured CSDs for Cases 3, 4 and 5 in Table 1, and Figures 8B, 9B and 10B represent the API concentration and the temperature profile along the crystallizer for the same cases. Comparisons are also made between the 
modelled yield and the yield during isothermal conditions.

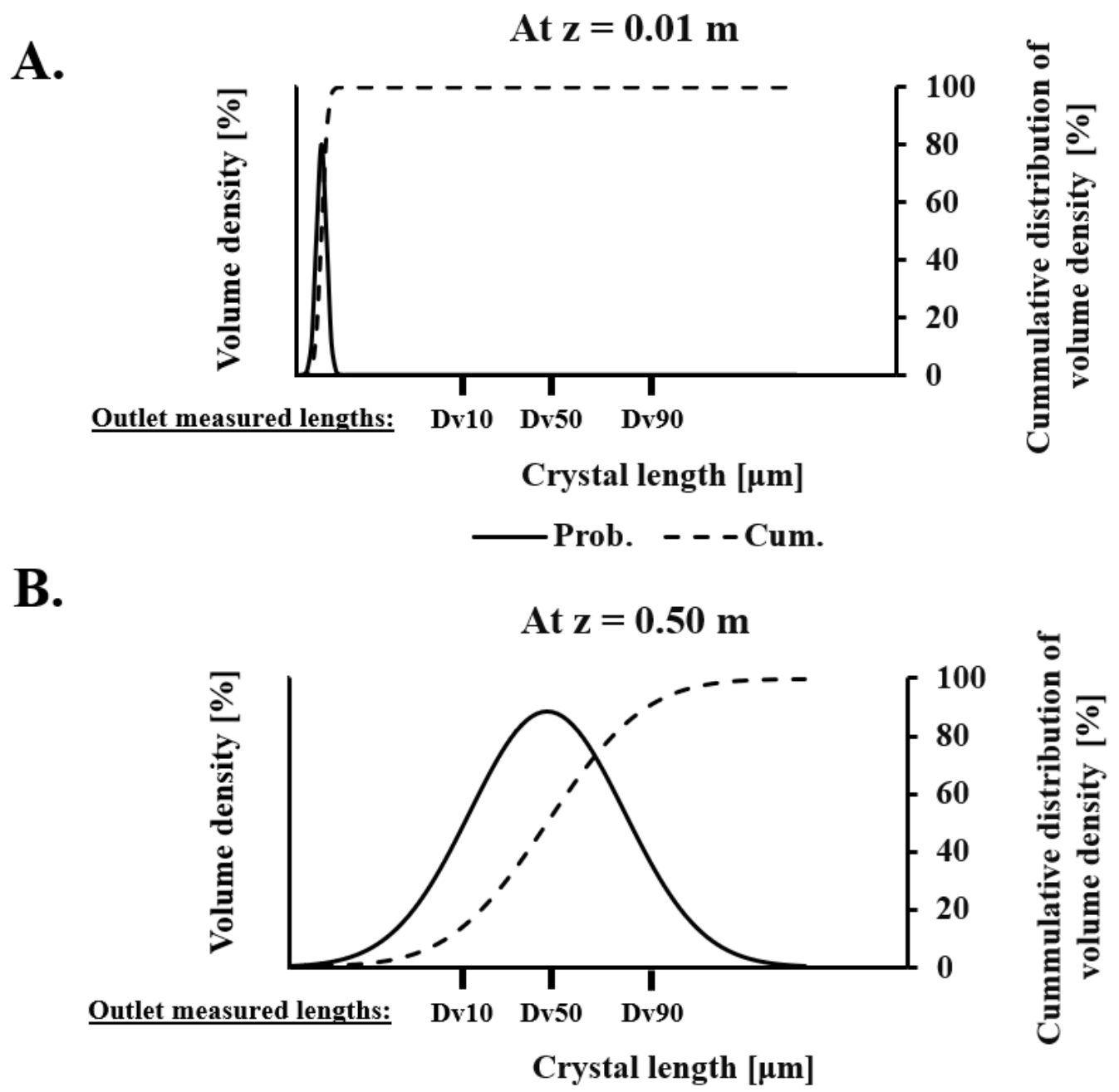

Figure 5: A. The narrow volume distribution and its cumulative distribution close to the crystallizer inlet $(z=0.01 \mathrm{~m})$ along with the Dv10, Dv50, and Dv90 lengths measured in the outlet (Table 2). B. The volume distribution and its cumulative distribution of the crystals measured at the crystallizer outlet $(z=0.5 \mathrm{~m})$ along with the measured lengths Dv10, Dv50, and Dv90 (Table 2). 


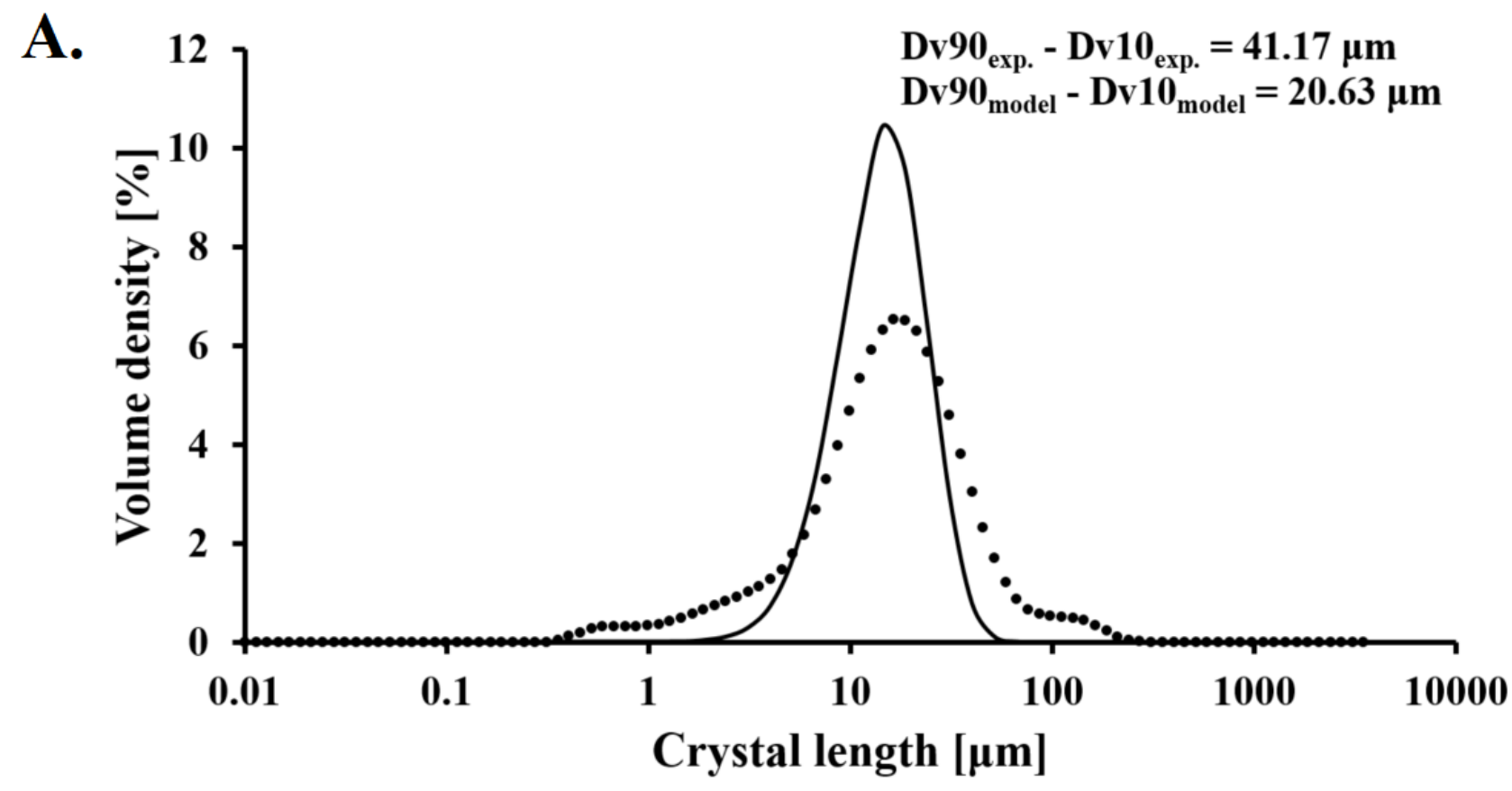

- Exp. - Model

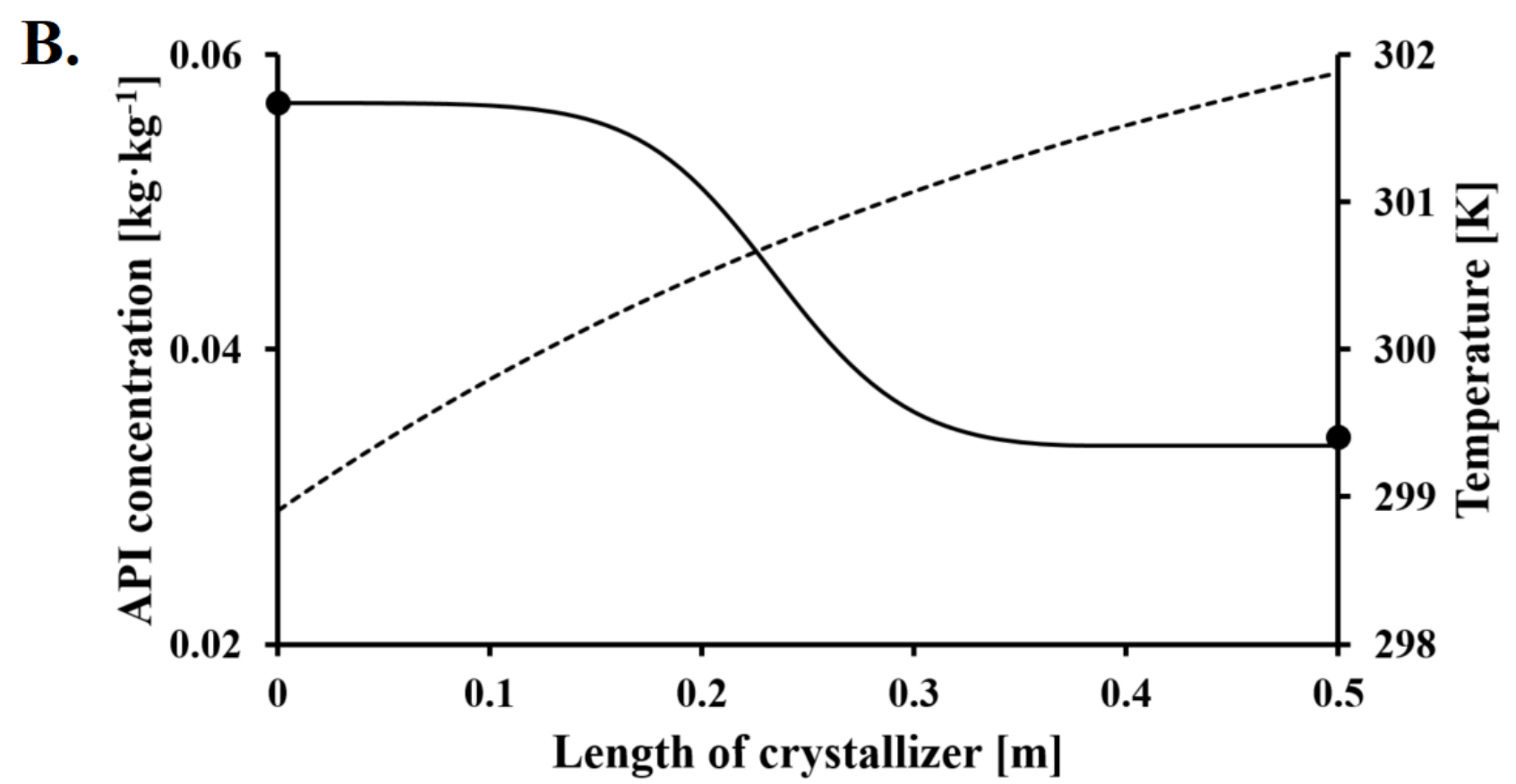

- Exp. - Model ---- Temp.

Figure 6: A. Volume density for Case 1 in Table 1. The experimental conditions were $S=2.40, Q_{\text {sol }}=2 \mathrm{~mL} / \mathrm{min}$, and $Q_{a n t i}=4 \mathrm{~mL} / \mathrm{min}$. B. API concentration and temperature profile for Case 1 in Table 1. Modelled yield equals $41 \%$ and is less than $30 \%$ when the temperature remains constant at $25^{\circ} \mathrm{C}$. 


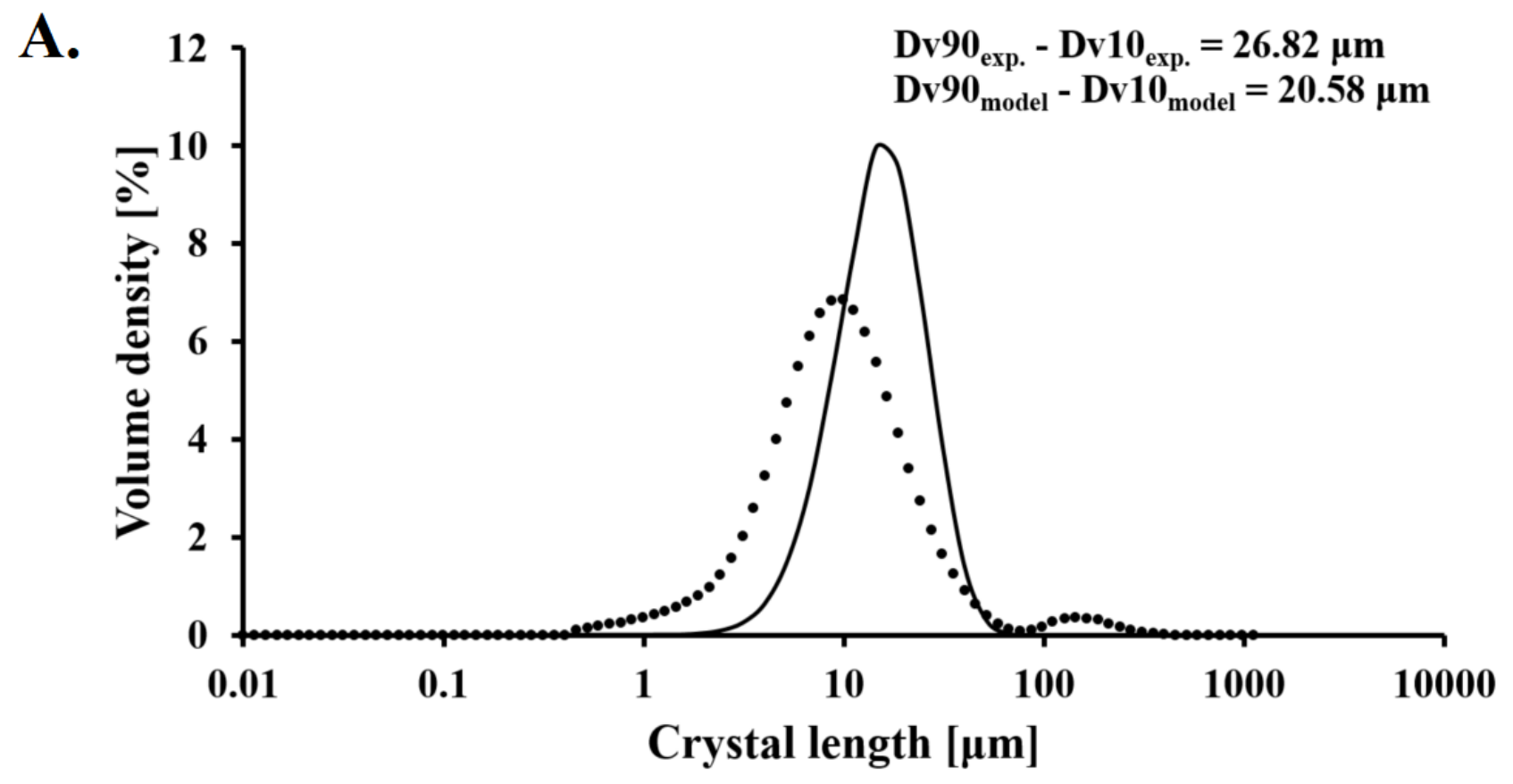

- Exp. - Model

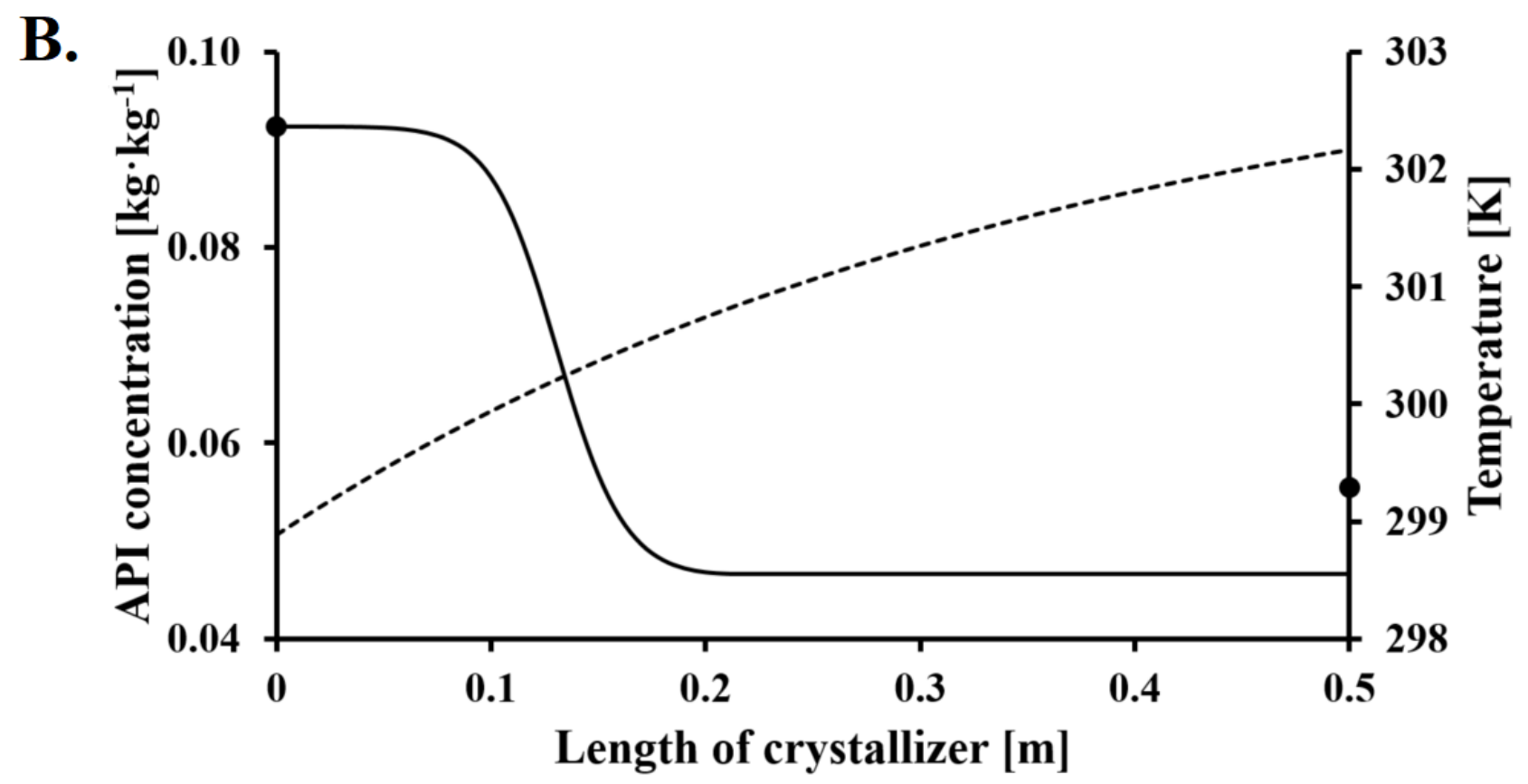

- Exp. - Model ---- Temp.

Figure 7: A. Volume density for Case 2 in Table 1. The experimental conditions were $S=2.42, Q_{\text {sol }}=2 \mathrm{~mL} / \mathrm{min}$, and $Q_{\text {anti }}=3 \mathrm{~mL} / \mathrm{min}$. B. API concentration and temperature profile for Case 2 in Table 1. Modelled yield equals $50 \%$ and is less than $16 \%$ when the temperature remains constant at $25^{\circ} \mathrm{C}$. 


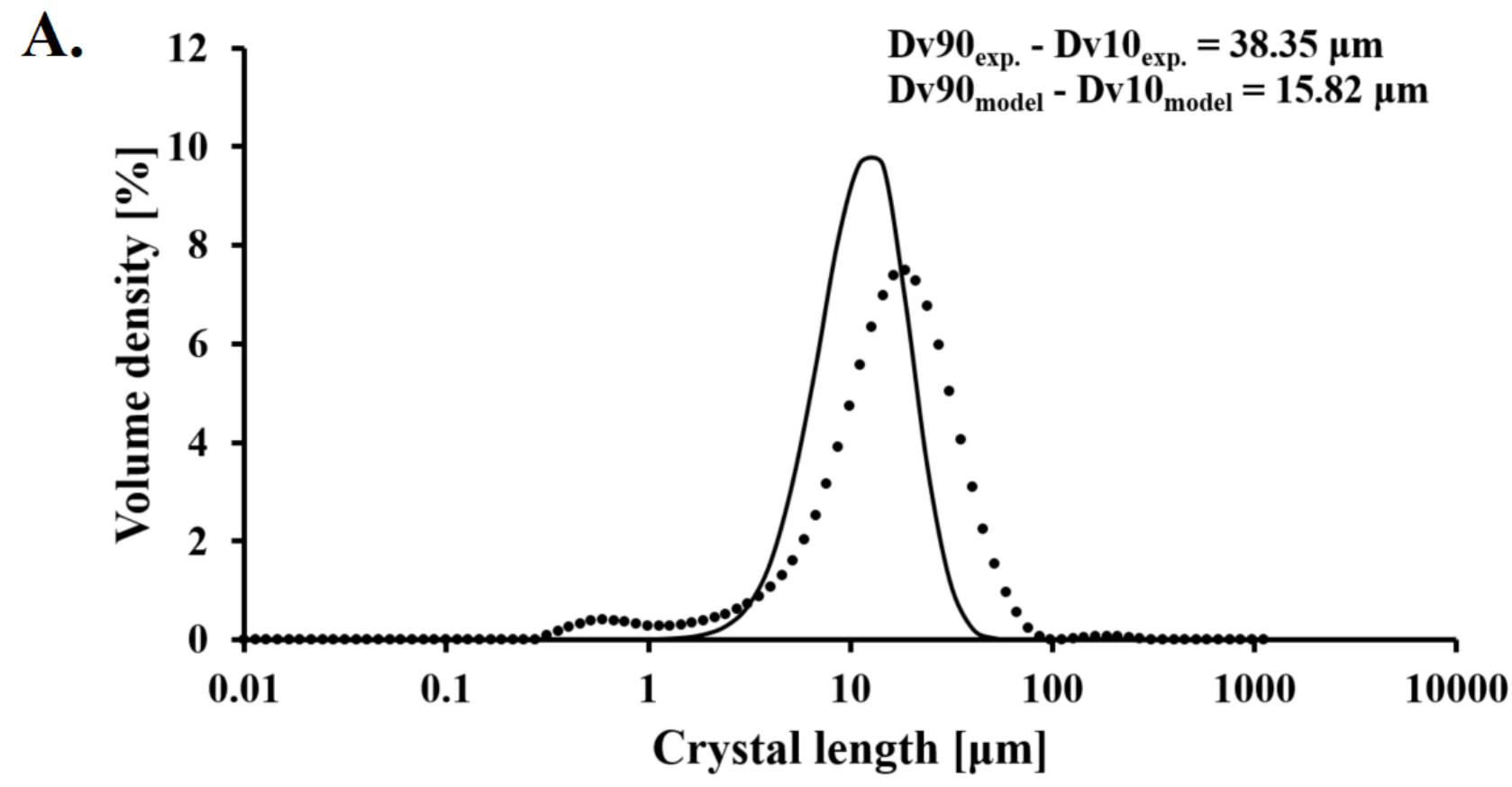

- Exp. - Model

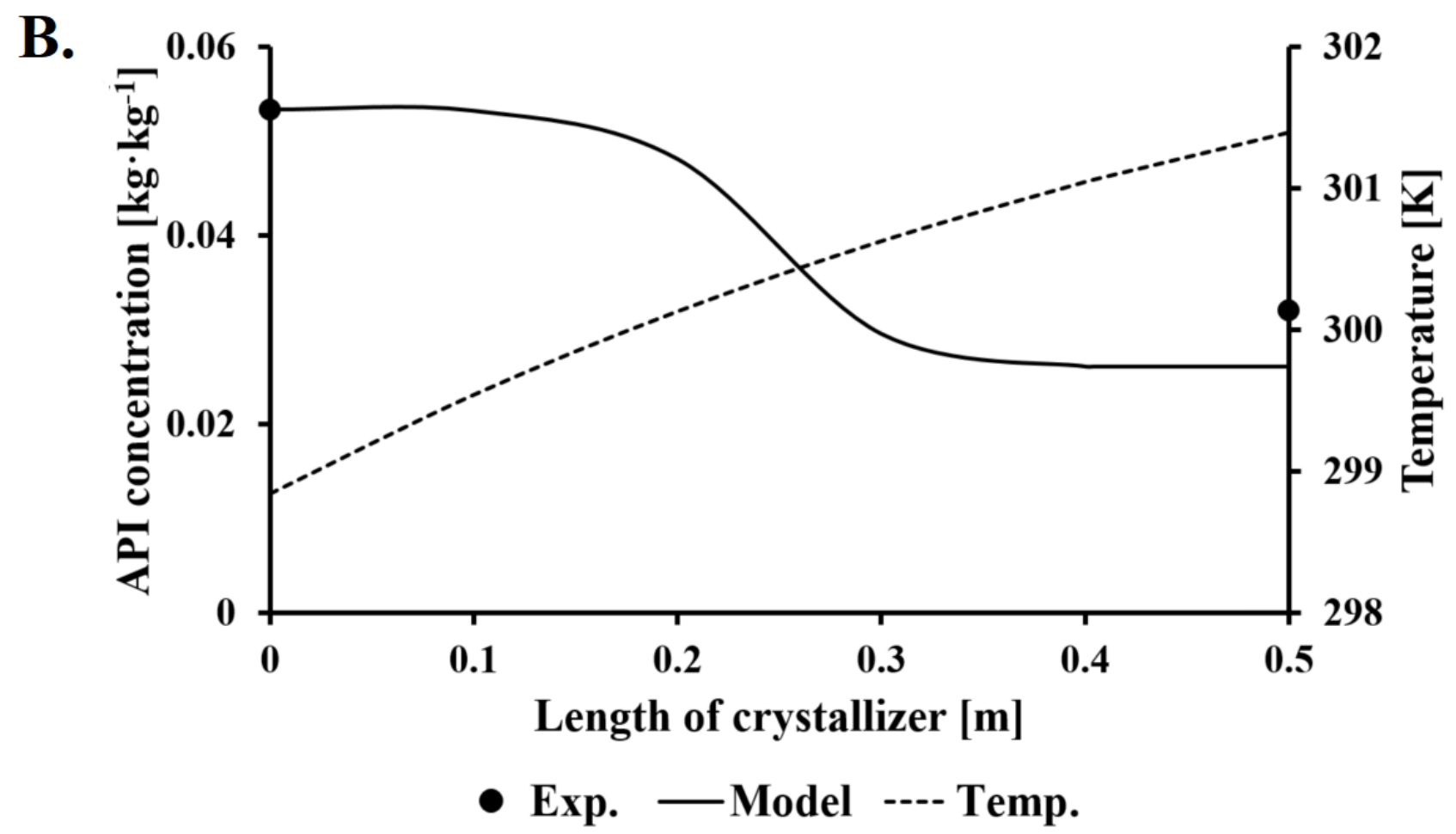

Figure 8: A. Predictive volume density for Case 3 in Table 2. The experimental conditions were $S=2.67, Q_{\text {sol }}=2 \mathrm{~mL} / \mathrm{min}$, and $Q_{a n t i}=6 \mathrm{~mL} / \mathrm{min}$. B. Predictive API concentration and temperature profile for Case 3 in Table 1 . Modelled yield equals $51 \%$ and is less than $19 \%$ when the temperature remains constant at $25^{\circ} \mathrm{C}$. 


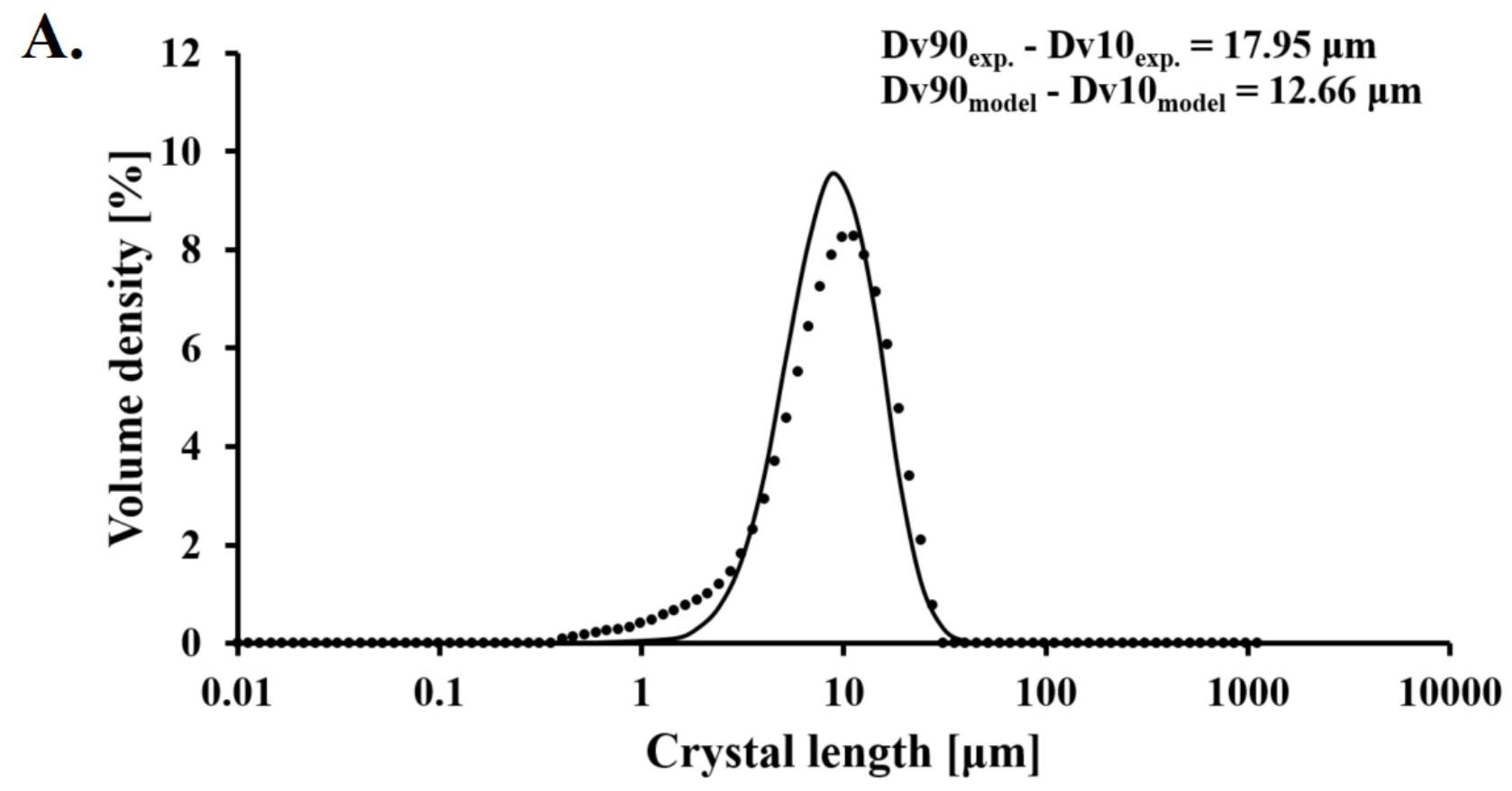

\section{- Exp. - Model}

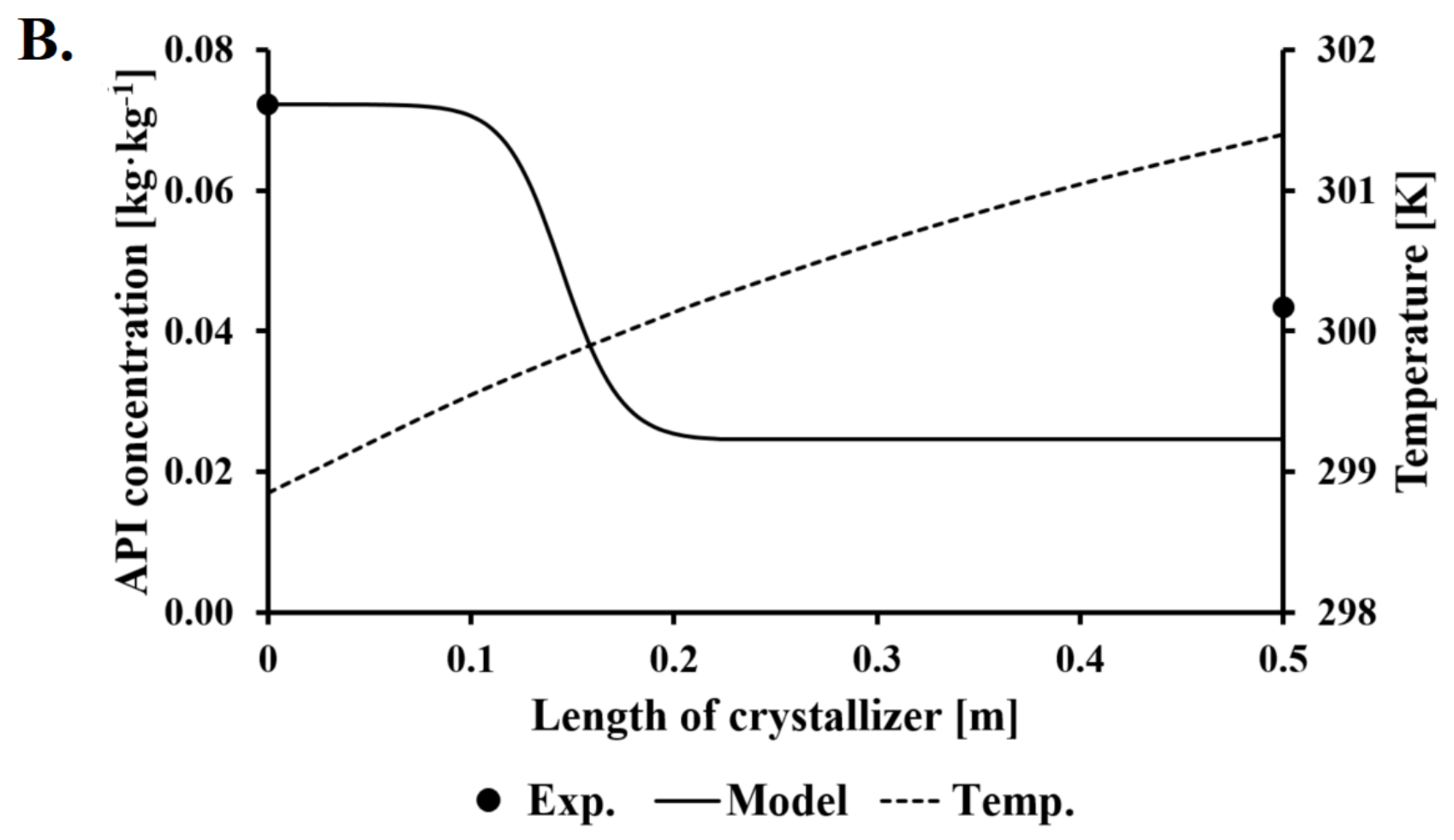

Figure 9: A. Predictive volume density for Case 4 in Table 2. The experimental conditions were $S=3.61, Q_{\text {sol }}=2 \mathrm{~mL} / \mathrm{min}$, and $Q_{a n t i}=6 \mathrm{~mL} / \mathrm{min}$. B. Predictive API concentration and temperature profile for Case 4 in Table 2. Modelled yield equals $69 \%$ and is less than $9 \%$ when the temperature remains constant at $25^{\circ} \mathrm{C}$. 


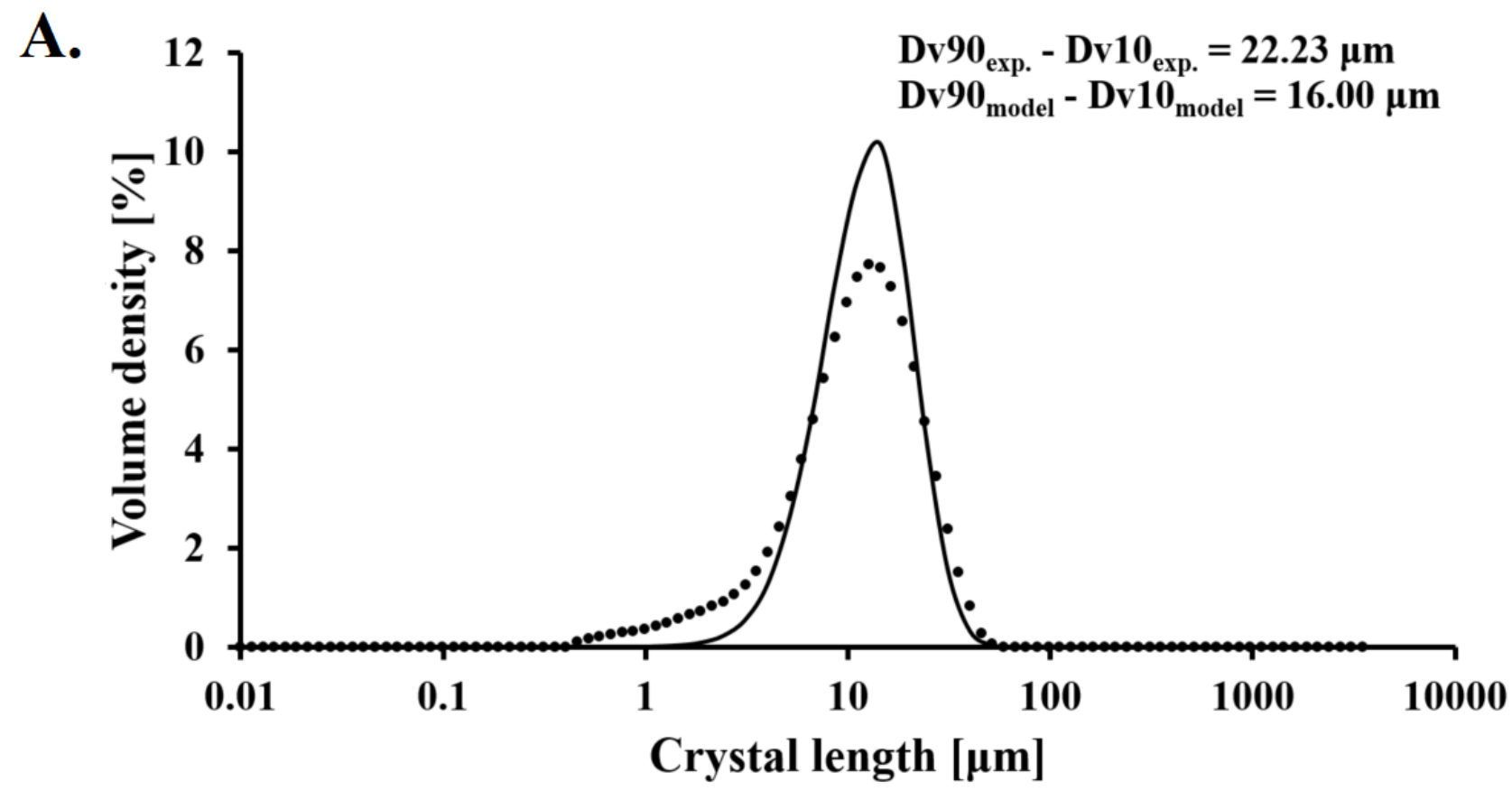

- Exp. - Model

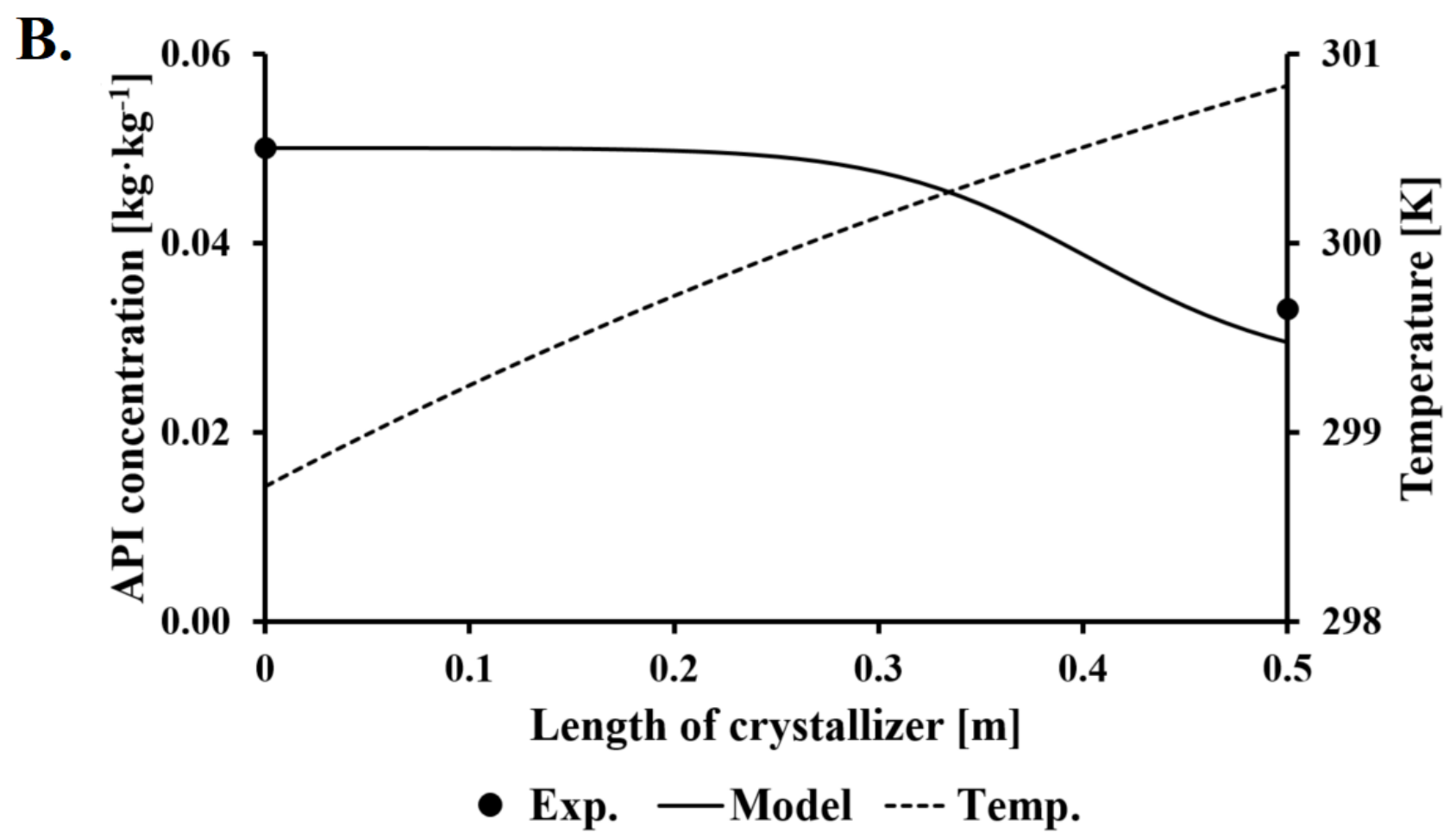

Figure 10: A. Predictive volume density for Case 5 in Table 2. The experimental conditions were $S=2.50, Q_{\text {sol }}=2 \mathrm{~mL} / \mathrm{min}$, and $Q_{a n t i}=9 \mathrm{~mL} / \mathrm{min}$. B. Predictive API concentration and temperature profile for Case 5 in Table 1 . Modelled yield equals $41 \%$ and is less than $32 \%$ when the temperature remains constant at $25^{\circ} \mathrm{C}$. 


\subsection{Discussion}

From an experimental point of view, particle size control is achieved by the application of ultrasound. Furthermore, the cavitating conditions can cause both attrition and breakage effects in the crystals, resulting in a lower mean crystal size. ${ }^{22,40}$ Parameter estimation showed that ultrasound increases the nucleation rate by two orders of magnitude, but its mechanistic effect on crystal growth still remains unclear. Comparing our produced crystals with reported crystal sizes obtained with seeds ${ }^{41,42}$ (Fiqures $6 \mathrm{~A}, 7 \mathrm{~A}, 8 \mathrm{~A}, 9 \mathrm{~A}$, and 10A) it is observed that the average size is one order of magnitude lower. In previous experiments, it has been shown that the supersaturation ratio affects the size of the produced crystals. ${ }^{17}$ The higher the supersaturation ratio, the higher is the nucleation rate and the more nuclei are produced resulting in a smaller final crystal size. However, the crystal size is not diminished after a certain threshold in supersaturation. ${ }^{17}$ For this reason, our new expression for nucleation due to ultrasound (Eq. 15 and Figure 3) contains terms that are affected by changes in temperature and supersaturation ratio. However, based on our earlier work, ${ }^{17} \mathrm{a}$ difference of 6 to $9 \mu \mathrm{m}$ in the crystal size at different supersaturation ratio levels (observed in our experiments) is not quite significant. Hence, the cavitation that occurred during the ultrasound was considered the most important factor of generating crystals with lower sizes and refinement. The bubbles generated may act as nucleation centers that segregate the molecules and form cluster of molecules. ${ }^{43,44}$

The thorough sensitivity analysis performed in our system helps to identify the parameters that have the most significant impact on specific outputs. These important parameters are specifically used in the empirical expressions to describe the nucleation rate during ultrasound application, the secondary nucleation and the growth. This step was necessary prior to parameter estimation. Then, the maximum likelihood algorithm estimated the significant parameters along with their confidence interval. The estimated nucleation rate is anticipated to be large for low ultrasound frequencies. The cavitation bubbles caused by the ultrasound application are considered the most critical factor for the parameter values in the nucleation 
rate equations. As for the ultrasound frequency, the higher the frequency, the lower the rate of generation of cavitation bubbles, which reduces the nucleation rate. ${ }^{45}$ Applying low frequency ultrasound results in small crystals, in contrast to the high frequency case where the crystal distributions are similar to silent conditions. ${ }^{46}$ However, within the low frequencies, the application of ultrasound in the range of $30-166 \mathrm{kHz}$ results in similar crystal size distributions. ${ }^{46}$ Furthermore, as long as operating at lower ultrasound power does not decrease the cavitation intensity significantly, the yield will be higher as the temperature increase is limited. ${ }^{3}$

Concerning the predictability of our model, it is shown in Figures 6A, 7A, 8A, 9A and 10A that the modelled crystal size distribution is within the observed Dv10 and Dv90 values. Deviations in capturing the exact Dv10 and Dv90 values are expected as our work is based on similar studies which removed the aggregation and breakage terms during the model development. However, comparison of the modelled and experimental Dv90 - Dv10 terms show that the proposed model can reproduce the crystallization of aspirin qualitatively in a plug flow crystallizer. ${ }^{10}$

Our work also considers the temperature increase in our system during the mixing and the ultrasound application. Although the solvent and the antisolvent have the same temperature of $298 \mathrm{~K}$ before the crystallizer inlet, Fiqures $6 \mathrm{~B}, 7 \mathrm{~B}, 8 \mathrm{~B}, 9 \mathrm{~B}$, and $10 \mathrm{~B}$ show how much it increases at $\mathrm{z}=0 \mathrm{~m}$ due to mixing. From empirical models,${ }^{25}$ the heat of mixing depends on the antisolvent content, but in our experiments, this heating raised the temperature up to $1^{\circ} \mathrm{C}$. Simultaneously, the final temperature increased by roughly $3-5^{\circ} \mathrm{C}$ with the use of ultrasound with a power of $24 \mathrm{~W}$. In our experiments, the initial supersaturation ratio was high, greater than 2 , the antisolvent content was greater than $65 \%$, and a $3-5^{\circ} \mathrm{C}$ increase in temperature results in an increase of solubility greater than $20 \% .{ }^{24}$ Areas of small antisolvent content were avoided because a greater amount of API is dissolved initially and this might cause fouling when the crystals are formed. As for the simulated temperature increase in our analysis, using data from literature and calorimetric powers at different ultrasound powers, 
the model is able to capture the measured heating in the experiments. The ability of our model to capture the temperature profile might be quite significant in longer crystallizers, as it can suggest the use of lower ultrasound power for lower temperature increase when cavitation bubbles at different powers have the same impact on nucleation rates.

We also observed that the increased solubility associated with the temperature increase reduces the yield of our system. Compared to reaching a steady state without temperature increase (see Figure 4), the lowest decrease in yield was $9 \%$ for Case 4, and the maximum decrease in yield of $32 \%$ was found for Case 5. The growth rate (modelled by Eq. 17) depends on the product of $C_{\text {sat }}(S-1)$, which means that the yield and API consumption are larger when the supersaturation ratio is higher, and the antisolvent content is lower as then the difference between the actual API concentration and its equilibrium solubility is high. For instance, this is visible for Cases 2 and 4 (Figures 6B and 8B) where the API consumption is quite fast along the crystallizer length.

Our model meaningfully adapts to each of the experiments conducted during the antisolvent crystallization of water, ethanol, and aspirin. Furthermore, we studied the crystal growth in a wide antisolvent content range (67\%-87\% - Table 1), which is then also applicable to the study of multisegment multiaddition systems. ${ }^{8}$ The proposed framework has been developed using a variety of assumptions and lab-scale experiments. However, used in tandem with more enlarged crystallizers and different geometries, the developed work may enable dynamic antisolvent crystallization modelling. It also provides insight into the trajectory of the crystals within the crystallizer and presents crystal growth in tubular crystallizers as avenues of future research.

\section{Conclusions}

The ultrasound-assisted antisolvent crystallization of aspirin from ethanol water in a continuous tubular crystallizer has been studied, showing that crystal sizes can become smaller 
with a more narrow CSD. For modelling the crystal sizes at different experimental conditions in flow rates and API initial concentrations, empirical expressions were employed in the nucleation rate due to ultrasound, and in the heat generated from ultrasound and mixing. These empirical expressions were developed based on conducted experiments. Global sensitivity analysis revealed the critical parameters in the nucleation and growth terms. Estimating the critical parameters, the model can predict the crystal size distribution and the yield of the system in experiments at different supersaturation ratio and antisolvent content. The model is practical in that (1) measurable input parameters have been obtained from typical crystallization protocols, (2) from thermophysical data that are readily available in the literature, (3) it captures the crystal growth along the crystallizer, and (4) it predicts the crystal sizes. The empirical expressions used in this work should be evaluated for the scale-up of continuous crystallizers to industrially relevant throughputs.

\section{Abbreviations}

ASA, Acetyl-Salicylic acid, Aspirin

API, active pharmaceutical ingredient

CFD, computational fluid dynamics

CSD, crystal size distribution

MSMPR, mixed-suspension, mixed-product removal

PBM, population balance models

\section{Variable Definitions}

$a_{c}$, heat transfer area per unit volume, $\left[\mathrm{m}^{2} / \mathrm{m}^{3}\right]$

$B_{\text {son }}$, nucleation rate from ultrasound, $\left[\# /\left(\mathrm{m}^{3} \mathrm{~s}\right)\right]$

$C$, API concentration in the solution, $\left[\mathrm{kg} / \mathrm{m}^{3}\right]$ 
$C_{0}$, initial API concentration, $\left[\mathrm{kg} / \mathrm{m}^{3}\right]$

$C_{\text {feed }}$, inlet API concentration, $\left[\mathrm{kg} / \mathrm{m}^{3}\right]$

$C_{\text {sat }}$, solute solubility, $[\mathrm{kg} / \mathrm{kg}]$

$C_{w}$, API concentration, $[\mathrm{kg} / \mathrm{kg}]$

$C p$, specific heat capacity of the mixture, $[\mathrm{J} /(\mathrm{kg} \mathrm{K})]$

$D, D_{n}$, total and n-order partial variances in sensitivity analysis, [-]

$d_{i n}$, inner diameter of the tubular crystallizer, $[\mathrm{m}]$

Dv, volume division diameter, $[\mathrm{m}]$

Dv10, the crystal size at which the cummulative volume distribution reaches $10 \%,[\mathrm{~m}]$

Dv50, the median for a volume distribution, $[\mathrm{m}]$

Dv90, the crystal size at which the cummulative volume distribution reaches $90 \%,[\mathrm{~m}]$

$f_{n}, \mathrm{n}$-order component function of an output in sensitivity analysis, [-]

$f_{\text {mix }}$, empirical factor in the heat of mixing, [-]

$G$, crystal growth rate, $[\mathrm{m} / \mathrm{s}]$

$k_{G 1}$, empirical parameter in growth rate, $[\mathrm{m} / \mathrm{s}]$

$k_{G 2}$, empirical parameter in growth rate, $[\mathrm{J} / \mathrm{mol}]$

$k_{j 1, \text { son }}$, empirical parameter in nucleation rate, $\left[\# /\left(\mathrm{m}^{3} \mathrm{~s}\right)\right]$

$k_{j 2, \text { son }}$, empirical parameter in nucleation rate, $[\mathrm{J} / \mathrm{mol}]$

$k_{j 3, \text { son }}$, empirical parameter in nucleation rate, [-]

$k_{s e c, 1}$, empirical parameter in nucleation rate, [\#/( $\left.\left.\mathrm{m}^{2} \mathrm{~s}\right)\right]$

$k_{s e c, 2}$, empirical parameter in nucleation rate, [-]

$K_{v}$, volume shape factor, [-]

loss, yield loss

$L$, crystal size, $[\mathrm{m}]$

$L_{0}$, the nuclei size, $[\mathrm{m}]$

$n$, crystal number density, $\left[\# /\left(\mathrm{m}^{3} \mathrm{~m}\right)\right]$

$N$, total number of measurements, [-] 
$n_{0}$, initial number probability density function for the CSD, [\#/( $\left.\left.\mathrm{m}^{3} \mathrm{~m}\right)\right]$

$n_{\text {feed }}$, the crystal size distribution at the inlet of the crystallizer, $\left[\# /\left(\mathrm{m}^{3} \mathrm{~m}\right)\right]$

$N E$, number of experiments, [-]

$N M$, number of measurements, [-]

$N V$, number of variables, [-]

$p$, estimated parameter set, [-]

$p_{i, j}$, parameters used in solubility estimation, [-]

$P_{\text {cal }}$, calorimetric ultrasound power, $\left[\mathrm{J} /\left(\mathrm{m}^{3} \mathrm{~s}\right)\right]$

$P_{n e t, U S}$, applied power of ultrasound, $[\mathrm{J} / \mathrm{s}]$

$Q_{\text {anti }}$, volume flowrate of antisolvent, $\left[\mathrm{m}^{3} / \mathrm{s}\right]$

$Q_{\text {solv }}$, volume flowrate of solvent and solute, $\left[\mathrm{m}^{3} / \mathrm{s}\right]$

$R$, ideal gas constant, $[\mathrm{J} /(\operatorname{mol} \mathrm{K})]$

$S$, supersaturation ratio, [-]

$S_{n}$, n-order sensitivity indices, [-]

$t$, time, [s]

$T$, temperature of the mixture, $[\mathrm{K}]$

$T_{\text {feed }}$, inlet temperature of the mixture, [K]

$T_{\text {in }}$, initial temperature of the mixture in the crystallizer, $[\mathrm{K}]$

$T_{w}$, temperature of the cooling water, $[\mathrm{K}]$

$U$, overall heat transfer coefficient, $\left[\mathrm{J} /\left(\mathrm{m}^{2} \mathrm{~s} \mathrm{~K}\right)\right]$

$V$, volume of crystals over volume of the slurry, $\left[\mathrm{m}^{3} / \mathrm{m}^{3}\right]$

$V_{\%}$, volume density, [-]

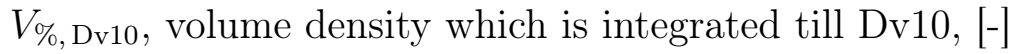

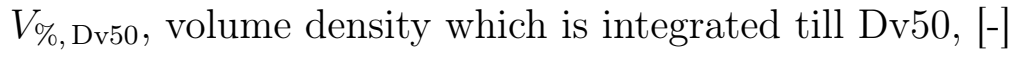

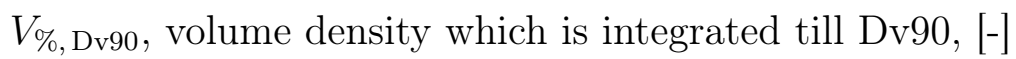

$v_{z}$, slurry velocity, $[\mathrm{m} / \mathrm{s}]$

$w$, antisolvent content, [-] 
yield, yield of crystals, [-]

$z$, axial position in the crystallizer, [m]

$z_{\text {max }}$, maximum axial position in the crystallizer, $[\mathrm{m}]$

$\Delta H_{\text {mix }}$, enthalpy of mixing, $[\mathrm{J} / \mathrm{kg}]$

$\zeta$, model output, [-]

$\bar{\zeta}$, measured output, [-]

$\theta$, temperature $\left[{ }^{\circ} \mathrm{C}\right]$

$\mu_{i}, i^{\text {th }}$ moment of the size distribution, $\left[\mathrm{m}^{i} / \mathrm{m} 3\right]$

$\rho$, mixture density, $\left[\mathrm{kg} / \mathrm{m}^{3}\right]$

$\rho_{c}$, crystal density, $\left[\mathrm{kg} / \mathrm{m}^{3}\right]$

$\sigma$, standard deviation, [-]

$\Phi$, optimization function in maximum likelihood estimator

\section{Acknowledgement}

This work was funded by the Agency for Innovation and Entrepreneurship (VLAIO) and Catalisti (grant number PIF HBC.2017.0442). S.K. acknowledges funding from the European Research Council under the ERC Starting Grant Agreement n.677169-MicroParticleControl. M.N.H. is supported by the European Union's Horizon 2020 research and innovation program under the Marie Sklodowska-Curie grant agreement No 721290 (Project website: http://cosmicetn.eu/).

\section{Supporting Information Available}

The following files are available free of charge.

The Supplementary Material contains details about the calorimetric power when applying ultrasound, the heat of mixing, the solute solubility and the method used for global sensitivity analysis. 


\section{References}

(1) Gao, Z.; Rohani, S.; Gong, J.; Wang, J. Recent developments in the crystallization process: Toward the pharmaceutical industry. Engineering 2017, 3, 343-353.

(2) Yang, X.; Acevedo, D.; Mohammad, A.; Pavurala, N.; Wu, H.; Brayton, A. L.; Shaw, R. A.; Goldman, M. J.; He, F.; Li, S.; Fisher, R. J.; O'Connor, T. F.; Cruz, C. N. Risk considerations on developing a continuous crystallization system for carbamazepine. Org. Process Res. Dev. 2017, 21, 1021-1033.

(3) Hussain, M. N.; Jordens, J.; John, J. J.; Braeken, L.; Van Gerven, T. Enhancing pharmaceutical crystallization in a flow crystallizer with ultrasound: Anti-solvent crystallization. Ultrason. Sonochem. submitted,

(4) Lai, T.-T. C.; Cornevin, J.; Ferguson, S.; Li, N.; Trout, B. L.; Myerson, A. S. Control of polymorphism in continuous crystallization via mixed suspension mixed product removal systems cascade design. Cryst. Growth Des. 2015, 15, 3374-3382.

(5) Baxendale, I. R.; Braatz, R. D.; Hodnett, B. K.; Jensen, K. F.; Johnson, M. D.; Sharratt, P.; Sherlock, J.-P.; Florence, A. J. Achieving continuous manufacturing: Technologies and approaches for synthesis, workup, and isolation of drug substance. May 20-21, 2014 Continuous Manufacturing Symposium. J. Pharm. Sci. 2015, 104, 781-791.

(6) Zhang, D.; Xu, S.; Du, S.; Wang, J.; Gong, J. Progress of pharmaceutical continuous crystallization. Engineering 2017, 3, 354-364.

(7) Ramkrishna, D., Ed. Population balances: Theory and applications to particulate systems in engineering; Elsevier: San Diego, CA, 2000.

(8) Su, Q.; Benyahia, B.; Nagy, Z. K.; Rielly, C. D. Mathematical modeling, design, and optimization of a multisegment multiaddition plug-flow crystallizer for antisolvent crystallizations. Org. Process Res. Dev. 2015, 19, 1859-1870. 
(9) Su, Q.; Nagy, Z. K.; Rielly, C. D. Pharmaceutical crystallisation processes from batch to continuous operation using MSMPR stages: Modelling, design, and control. Chem. Eng. Process. 2015, 89, 41-53.

(10) Kordylla, A.; Krawczyk, T.; Tumakaka, F.; Schembecker, G. Modeling ultrasoundinduced nucleation during cooling crystallization. Chem. Eng. Sci. 2009, 64, 16351642.

(11) Dodds, J.; Espitalier, F.; Louisnard, O.; Grossier, R.; David, R.; Hassoun, M.; Baillon, F.; Gatumel, C.; Lyczko, N. The effect of ultrasound on crystallisation-precipitation processes: Some examples and a new segregation model. Part. Part. Syst. Charact. 2007, 24, 18-28.

(12) Fernandez Rivas, D.; Kuhn, S. Synergy of Microfluidics and Ultrasound. Top. Curr. Chem. 2016, 374, 70-99.

(13) Kiss, A. A.; Geertman, R.; Wierschem, M.; Skiborowski, M.; Gielen, B.; Jordens, J.; John, J. J.; Van Gerven, T. Ultrasound-assisted emerging technologies for chemical processes. J. Chem. Technol. Biotechnol. 2018, 93, 1219-1227.

(14) Fatemi, N.; Dong, Z.; Van Gerven, T.; Kuhn, S. Microbubbles as heterogeneous nucleation sites for crystallization in continuous microfluidic devices. Langmuir 2018, 35, 60-69.

(15) Jiang, M.; Papageorgiou, C. D.; Waetzig, J.; Hardy, A.; Langston, M.; Braatz, R. D. Indirect ultrasonication in continuous slug-flow crystallization. Cryst. Growth Des. 2015, $15,2486-2492$.

(16) Rossi, D.; Jamshidi, R.; Saffari, N.; Kuhn, S.; Gavriilidis, A.; Mazzei, L. Continuousflow sonocrystallization in droplet-based microfluidics. Cryst. Growth Des. 2015, 15, $5519-5529$. 
(17) Jordens, J.; Canini, E.; Gielen, B.; Van Gerven, T.; Braeken, L. Ultrasound assisted particle size control by continuous seed generation and batch growth. Crystals 2017, 7, 195-214.

(18) Gielen, B.; Jordens, J.; Janssen, J.; Pfeiffer, H.; Wevers, M.; Thomassen, L.; Braeken, L.; Van Gerven, T. Characterization of stable and transient cavitation bubbles in a milliflow reactor using a multibubble sonoluminescence quenching technique. Ultrason. Sonochem. 2015, 25, 31-39.

(19) Jamshidi, R.; Rossi, D.; Saffari, N.; Gavriilidis, A.; Mazzei, L. Investigation of the effect of ultrasound parameters on continuous sonocrystallization in a millifluidic device. Cryst. Growth Des. 2016, 16, 4607-4619.

(20) Nalesso, S.; Bussemaker, M. J.; Sear, R. P.; Hodnett, M.; Lee, J. A Review on Possible Mechanisms of Sonocrystallisation in Solution. Ultrason. Sonochem. 2019,

(21) Sivabalan, R.; Gore, G.; Nair, U.; Saikia, A.; Venugopalan, S.; Gandhe, B. Study on ultrasound assisted precipitation of CL-20 and its effect on morphology and sensitivity. J. Hazard. Mater. 2007, 139, 199-203.

(22) Ramisetty, K. A.; Pandit, A. B.; Gogate, P. R. Ultrasound-assisted antisolvent crystallization of benzoic acid: Effect of process variables supported by theoretical simulations. Ind. Eng. Chem. Res. 2013, 52, 17573-17582.

(23) Brown, C. J.; Ni, X.-W. Determination of metastable zone width, mean particle size and detectable number density using video imaging in an oscillatory baffled crystallizer. CrystEngComm 2012, 14, 2944-2949.

(24) Lindenberg, C.; Krättli, M.; Cornel, J.; Mazzotti, M.; Brozio, J. Design and optimization of a combined cooling/antisolvent crystallization process. Cryst. Growth Des. 2008, 9, 1124-1136. 
(25) Peeters, D.; Huyskens, P. Endothermicity or exothermicity of water/alcohol mixtures. J. Mol. Struct. 1993, 300, 539-550.

(26) John, J. J.; Kuhn, S.; Braeken, L.; Van Gerven, T. Temperature controlled interval contact design for ultrasound assisted liquid-liquid extraction. Chem. Eng. Res. Des. 2017, 125, 146-155.

(27) MPI Double \& Triple Frequency Converters. http://www.mpi-ultrasonics . com/pdf/ mpi_double_triple_frequency_converters.pdf, Accessed: 2019-05-03.

(28) Kwon, J. S.-I.; Nayhouse, M.; Orkoulas, G.; Christofides, P. D. Crystal shape and size control using a plug flow crystallization configuration. Chem. Eng. Sci. 2014, 119, 30-39.

(29) Fluorotherm: Ultrapure shell and tube heat exchanger. https://www.fluorotherm. com/wp-content/uploads/2014/04/UltrapureShellAndTubeHeatExchanger .pdf, Accessed: 2018-09-30.

(30) Lemmon, E. W.; Bell, I.; Huber, M. L.; McLinden, M. O. NIST Standard Reference Database 23: Reference Fluid Thermodynamic and Transport Properties-REFPROP, Version 10.0, National Institute of Standards and Technology. 2018; https://www . nist.gov/srd/refprop.

(31) Danahy, B.; Minnick, D.; Shiflett, M. Computing the composition of ethanol-water mixtures based on experimental density and temperature measurements. Fermentation 2018, 4, 72-78.

(32) Van der Heijden, A.; Van der Eerden, J.; Van Rosmalen, G. The secondary nucleation rate: A physical model. Chem. Eng. Sci. 1994, 49, 3103-3113.

(33) Frawley, P. J.; Mitchell, N. A.; O’Ciardhá, C. T.; Hutton, K. W. The effects of super- 
saturation, temperature, agitation and seed surface area on the secondary nucleation of paracetamol in ethanol solutions. Chem. Eng. Sci. 2012, 75, 183-197.

(34) Cogoni, G.; de Souza, B. P.; Frawley, P. J. Particle size distribution and yield control in continuous plug flow crystallizers with recycle. Chem. Eng. Sci. 2015, 138, 592-599.

(35) Ziehn, T.; Tomlin, A. Global sensitivity analysis of a 3D street canyon model-Part I: The development of high dimensional model representations. Atmos. Environ. 2008, 42, 1857-1873.

(36) PSE, gPROMS Advanced User Guide; Process Systems Enterprise: London, UK, 2004; p 37.

(37) Bari, A. H.; Pandit, A. B. Sequential crystallization parameter estimation method for determination of nucleation, growth, breakage, and agglomeration kinetics. Ind. Eng. Chem. Res. 2018, 57, 1370-1379.

(38) Schall, J. M.; Mandur, J. S.; Braatz, R. D.; Myerson, A. S. Nucleation and growth kinetics for combined cooling and antisolvent crystallization in a mixed-suspension, mixed-product removal system: Estimating solvent dependency. Cryst. Growth Des. 2018, 18, 1560-1570.

(39) Gábor, A.; Banga, J. R. Robust and efficient parameter estimation in dynamic models of biological systems. BMC Syst. Biol. 2015, 9, 74-98.

(40) Rasche, M. L.; Zeiger, B. W.; Suslick, K. S.; Braatz, R. D. Mathematical modelling of the evolution of the particle size distribution during ultrasound-induced breakage of aspirin crystals. Chem. Eng. Res. Des. 2018, 132, 170-177.

(41) Eder, R. J.; Radl, S.; Schmitt, E.; Innerhofer, S.; Maier, M.; Gruber-Woelfler, H.; Khinast, J. G. Continuously seeded, continuously operated tubular crystallizer for the 
production of active pharmaceutical ingredients. Cryst. Growth Des. 2010, 10, 22472257.

(42) Besenhard, M. O.; Hohl, R.; Hodzic, A.; Eder, R. J.; Khinast, J. G. Modeling a seeded continuous crystallizer for the production of active pharmaceutical ingredients. Cryst. Res. Technol. 2014, 49, 92-108.

(43) Kiani, H.; Zhang, Z.; Delgado, A.; Sun, D.-W. Ultrasound assisted nucleation of some liquid and solid model foods during freezing. Food Res. Int. 2011, 44, 2915-2921.

(44) Nalajala, V. S.; Moholkar, V. S. Investigations in the physical mechanism of sonocrystallization. Ultrason. Sonochem. 2011, 18, 345-355.

(45) Jordens, J.; Gielen, B.; Braeken, L.; Van Gerven, T. Determination of the effect of the ultrasonic frequency on the cooling crystallization of paracetamol. Chem. Eng. Process. 2014, 84, 38-44.

(46) Jordens, J.; Appermont, T.; Gielen, B.; Van Gerven, T.; Braeken, L. Sonofragmentation: Effect of ultrasound frequency and power on particle breakage. Cryst. Growth Des. 2016, 16, 6167-6177. 